Article

\title{
Selective Uptake of Carboxylated Multi-Walled Carbon Nanotubes by Class A Type 1 Scavenger Receptors and Impaired Phagocytosis in Alveolar Macrophages
}

\author{
Ruhung Wang ${ }^{1,2}$, Rishabh Lohray ${ }^{1, \dagger}$, Erik Chow ${ }^{3, \ddagger}$, Pratima Gangupantula ${ }^{1}$, Loren Smith ${ }^{2}$ \\ and Rockford Draper 1,2,* \\ 1 Department of Biological Sciences, The University of Texas at Dallas, 800 West Campbell Road, \\ Richardson, TX 75080, USA; ruhung.wang@utdallas.edu (R.W.); Rishabh.Lohray@bcm.edu (R.L.); \\ Pratima.Gangupantula@utdallas.edu (P.G.) \\ 2 Department of Chemistry \& Biochemistry, The University of Texas at Dallas, 800 West Campbell Road, \\ Richardson, TX 75080, USA; Loren@utdallas.edu \\ 3 Department of Bioengineering, The University of Texas at Dallas, 800 West Campbell Road, \\ Richardson, TX 75080, USA; ec829@cornell.edu \\ * Correspondence: draper@utdallas.edu \\ $+\quad$ Present Affiliation: Baylor College of Medicine, School of Medicine, Houston, TX 77030, USA. \\ $\ddagger$ Present Affiliation: Meinig School of Biomedical Engineering, Cornell University, Ithaca, NY 14850, USA.
}

Received: 19 October 2020; Accepted: 27 November 2020; Published: 3 December 2020

\begin{abstract}
The production and applications of multi-walled carbon nanotubes (MWNTs) have increased despite evidence that MWNTs can be toxic. Recently, we reported that the binding of Pluronic ${ }^{\circledR}$ F-108 (PF108)-coated carboxylated MWNTs (C-MWNTs) to macrophages is inhibited by class A scavenger receptors (SR-As) antagonists (R. Wang et al., 2018. Nanotoxicology 12:677-690). The current study investigates the uptake of PF108-coated MWNTs by macrophages lacking SR-A1 and by CHO cells that ectopically express SR-A1. Macrophages without SR-A1 failed to take up C-MWNTs and CHO cells that expressed SR-A1 did take up C-MWNTs, but not pristine MWNTs (P-MWNTs) or amino-functionalized MWNTs (N-MWNTs). The dependence of C-MWNT uptake on SR-A1 is strong evidence that SR-A1 is a receptor for C-MWNTs. The consequences of SR-A1-dependent C-MWNT accumulation on cell viability and phagocytic activity in macrophages were also studied. C-MWNTs were more toxic than P-MWNTs and N-MWNTs in cell proliferation and colony formation tests. C-MWNTs reduced surface SR-A1 levels in RAW 264.7 cells and impaired phagocytic uptake of three known SR-A1 ligands, polystyrene beads, heat-killed E. coli, and oxLDL. Altogether, results of this study confirmed that SR-A1 receptors are important for the selective uptake of PF108-coated C-MWNTs and that accumulation of the C-MWNTs impairs phagocytic activity and cell viability in macrophages.
\end{abstract}

Keywords: nanomaterials; macrophages; class A type 1 scavenger receptors; cytotoxicity; macrophagenanoparticle interaction

\section{Introduction}

Carbon nanotubes (CNTs) are graphene sheets rolled into cylindrical tubes. Single-walled carbon nanotubes (SWNTs) contain a single graphene tube while multi-walled carbon nanotubes (MWNTs) contain multiple tubes concentrically nested inside each other. The light weight, strength, electrical and thermal conductivity of CNTs make them suited for applications in diverse fields including flexible 
electronics, medicine, reinforced composites, sensors, and Li-ion batteries [1-3]. The production of various CNT types is expected to exceed 15 kilotons/year by 2020 [3]. The increased production and use of CNTs raises the risk of unwanted exposure and subsequent toxicity. Sustained exposure has been shown to cause pulmonary inflammation [4,5], fibrosis [6], gene damage [7], and even mesothelioma [8] in lab animals. A better understanding of the pathology of CNT exposure is important to facilitate the design of less toxic CNT forms and to develop rational strategies for treating persons who may be accidentally exposed.

The surfaces of CNTs are often chemically functionalized, for example, by addition of carboxyl or amino groups, to tune their properties for increased dispersibility in aqueous solution, for decreased toxicity, or for higher drug load and targeting specificity in advanced drug delivery options. In nanomedicine, specific CNT functionalizations have been shown to facilitate the delivery of anticancer agents and biomolecules to target tissues for cancer therapy, thermal ablation therapy, gene therapy, immunotherapy, and for diagnostic applications [9]. However, these applications encounter a common significant challenge, where 30-99\% of nanoparticles administered in vivo are sequestered by liver macrophages [10], and the mechanisms underlying the interaction between CNTs and macrophages remain poorly understood.

Recently, we reported that both human and mouse alveolar macrophages accumulated far more Pluronic ${ }^{\circledR}$ F-108 (PF108)-coated carboxylated MWNTs (C-MWNTs) and carboxylated SWNTs (C-SWNTs) at $37^{\circ} \mathrm{C}$ than the non-functionalized pristine MWNTs (P-MWNTs) and SWNTs (P-SWNTs) [11]. In addition, more C-MWNTs than P-MWNTs bound to macrophages in direct binding assays at $4{ }^{\circ} \mathrm{C}$ [11]. These data suggested that there were cell surface receptors that bound C-MWNTs but not P-MWNTs. Since the binding of C-MWNTs and C-SWNTs to macrophages was inhibited by known antagonists of class A scavenger receptors [11], members of this receptor class may be involved in the specific uptake of carboxylated CNTs in macrophages.

Class A scavenger receptors (SR-As) are pattern recognition receptors expressed by various cell types including macrophages, endothelial cells, and dendritic cells [12-14]. There are six types of SR-As, classified by a consensus nomenclature, which all contain a collagenous domain believed to bind a wide variety of polyanionic ligands, including modified low density lipoproteins, polysaccharides, nucleic acids, and various bacteria [14]. Since C-MWNTs are polyanions, it is possible that they could be SR-A ligands. Dextran sulfate and fucoidan are known antagonists of SR-A ligands, and in previous work we noted that both of these compounds partially blocked the binding of C-MWNTs to RAW 264.7 macrophages [11]. In addition, RAW 264.7 cells express high levels of scavenger receptor A1 (SR-A1) [15], leading to the hypothesis that SR-A1 might be a receptor for C-MWNTs. However, polyanionic inhibitors may affect more than one type of SR-A and it is difficult to pinpoint which type may be interacting with C-MWNTs. One main objective of the present paper was to test the hypothesis that SR-A1 is a receptor for C-MWNTs by measuring C-MWNT accumulation by macrophages that lack SR-A1 and by Chinese Hamster Ovary K1 cell (CHO-K1) clones that have been transfected with mouse SR-A1 cDNA. SR-A1 deficient macrophages and wild type CHO-K1 that do not normally express SR-A1 failed to accumulate significant amounts of C-MWNTs, whereas SR-A1 expressing CHO-K1 clones did accumulate C-MWNTs, strong evidence that SR-A1 is a C-MWNT receptor.

Possible physiological consequences of C-MWNT accumulation on cell viability and SR-A1 function were also explored in the current study. RAW 264.7 cell proliferation and colony formation efficiency were impaired in a dose and time dependent manner after exposure to C-MWNTs. In addition, exposure of RAW 264.7 cells to C-MWNTs reduced the level of SR-A1 on their surface and reduced the uptake of three known SR-A1 ligands: polystyrene beads, heat-killed E. coli, and oxidized low density lipoprotein (oxLDL). 


\section{Materials and Methods}

\subsection{MWNTs and other Materials}

Three different research grade MWNT powders were used in this work, all purchased from NanoCyl (NanoCyl SA, Sambreville, Belgium). (1) Non-functionalized pristine MWNTs (P-MWNTs, NC3150 ${ }^{\mathrm{TM}}$ ); (2) Carboxyl-functionalized MWNTs (C-MWNTs, NC3151 ${ }^{\mathrm{TM}}$ ); and (3) Aminofunctionalized MWNTs (N-MWNTs, NC3152 ${ }^{\mathrm{TM}}$ ). The MWNTs were produced by the catalytic chemical vapor deposition process to an average outside diameter of $\sim 9.5 \mathrm{~nm}$, purified to $>95 \mathrm{wt} . \%$ carbon content and shortened to an average length of $<1.0 \mu \mathrm{m}$, according to the product specifications provided by the manufacturer. Proprietary surface modification methods were used by the manufacturer to introduce $<8.0 \mathrm{wt} . \%$ content of $-\mathrm{COOH}$ groups in the C-MWNT product and $<0.6 \mathrm{wt} . \%$ of $-\mathrm{NH}_{2}$ groups in the N-MWNT product. Additional physicochemical properties of these and other MWNT products, including bulk metal catalysts composition by energy dispersive X-ray spectroscopy (EDX) and surface chemical compositions by X-ray photoelectron spectroscopy (XPS), are available from previous work in the literature $[16,17]$. Caution: a fine particulate respirator and other appropriate personal protective equipment should be worn when handling dry MWNT powders.

Pluronic ${ }^{\circledR}$ F-108 (PF108) (cat. No. 542342), G418 disulfate salt solution (cat. No. G8168), IgG from mouse serum (cat. No. I5381), and Trypan Blue solution (cat. No. T8154) were purchased from Sigma Aldrich (St. Louis, MO, USA). Mouse SR-AI/MSR Alexa Fluor ${ }^{\circledR}$ 488-conjugated antibody (cat. No. FAB1797G), rat IgG2b Alexa Fluor ${ }^{\circledR}$ 488-conjugated isotype control antibody (cat. No. IC013G), mouse MARCO allophycocyanin (APC)-conjugated antibody (cat. No. FAB2956A), rat IgG1 APC-conjugated isotype control antibody (cat. No. IC005A), and flow cytometry (FCyt) staining buffer (cat. No. FC001) were purchased from R\&D Systems, Inc. (Minneapolis, MN, USA) and used as received. Non-functionalized fluorescent polystyrene beads with a nominal diameter of $1 \mu \mathrm{m}$ were acquired from Bangs Laboratories Inc. (cat. No. FSDG004, Fishers, Indiana). According to the manufacturer, the beads were produced by an emulsion polymerization technique resulting in a net negative surface charge. They were internally labeled with Dragon Green Dye (Ex: $480 \mathrm{~nm}$, Em: $520 \mathrm{~nm}$ ), using a solvent swelling/dye entrapment technique. Annexin V-FITC apoptosis detection kit (Invitrogen ${ }^{\mathrm{TM}}$ cat. No. V13242), heat-killed Alexa Fluor ${ }^{\circledR} 488$ conjugated Escherichia coli (K-12 strain) BioParticles $^{\mathrm{TM}}$ (Invitrogen ${ }^{\mathrm{TM}}$ cat. No. E13231), and oxidized low density lipoprotein from human plasma (Invitrogen ${ }^{\mathrm{TM}}$ cat. No. L34357) were purchased from Thermo Fisher Scientific (Waltham, MA, USA). Oxidized LDL uptake assay kit was purchased from Cayman Chemical (cat. No. 601180, Ann Arbor, MI, USA).

\subsection{Preparation and Characterization of PF108 MWNT Dispersions}

Pluronic ${ }^{\circledR}$ F-108 (PF108) is a non-ionic triblock copolymer, also known as poloxamer 338. PF108 and related poloxamers have been used as effective surfactants to prepare aqueous dispersions of hydrophobic nanomaterials, including MWNTs and SWNTs, for nanotoxicity studies [11,18,19]. A stock PF108 solution at $5 \mathrm{mM}$ concentration was prepared by dissolving PF108 powder in DI water purified using a Milli-Q system (Billerica, MA, USA), filtered through a $0.22 \mu \mathrm{m}$ membrane, and stored at $4{ }^{\circ} \mathrm{C}$ in the dark. All MWNT dispersions were prepared with a freshly diluted and filtered $0.2 \mathrm{mM}$ PF108 solution. To reduce potential endotoxin contaminants that could lead to ambiguous toxicity results, all MWNT powders were baked at $200{ }^{\circ} \mathrm{C}$ for $2 \mathrm{~h}$ [20] before PF108 solution was added. The sonication, centrifugation, and dialysis protocols described in our previous work $[18,19]$ were used to prepare PF108-coated MWNT dispersions. Note that the dialysis step is crucial to remove toxic PF108 products generated by sonication [18,21]. The prepared dispersions of $\mathrm{P}-, \mathrm{N}-$, and C-MWNTs in PF108 solution were denoted as PMPF, NMPF, and CMPF dispersions, respectively.

The concentration of MWNTs in each prepared dispersion was measured using the absorbance at $500 \mathrm{~nm}$. Dynamic light scattering (DLS) and zeta potential (ZP) analyses were used as part of a quality control routine for the preparation of all MWNT dispersions $[18,19]$. In addition, zeta potentials of all 
MWNT dispersions diluted to $\sim 50 \mu \mathrm{g} / \mathrm{mL}$ in water and in cell culture medium with $10 \%$ fetal bovine serum (FBS) were acquired at $25^{\circ} \mathrm{C}$ and $37^{\circ} \mathrm{C}$, respectively.

The physicochemical properties of the three MWNT powders provided by the manufacturer and the properties of PF108-coated MWNT dispersions prepared for this study are shown in Table 1. Note that the zeta potentials for C-MWNTs were slightly more negative than those for P- and N-MWNTs in water. Also, the zeta potential values were less negative for all MWNT types in medium with serum than in water, as expected due to the increase in salt and serum protein concentrations, and the C-MWNTs still had slightly more negative zeta potentials than P- or N-MWNTs.

\subsection{Cell Lines and Cell Culture}

Dulbecco's modified Eagle medium (DMEM) was purchased from Gibco (Grand Island, NY, USA). Ham's F-12K (ATCC ${ }^{\circledR}$ 30-2004) and RPMI 1640 (ATCC ${ }^{\circledR}$ 30-2001) media were purchased from the American Type Culture Collection (ATCC, Manassas, VA, USA). FBS was purchased from Atlanta Biologicals (Flowery Branch, GA, USA). Penicillin-streptomycin solution (100 U penicillin/0.1 mg streptomycin per $\mathrm{mL}$ ) was purchased from Sigma Aldrich and used only in terminal cultures. Gibco ${ }^{\mathrm{TM}}$ PBS-based enzyme-free cell dissociation buffer (cat. No. 13151-014), Accumax ${ }^{\mathrm{TM}}$ (cat. No. 00-4666-56), Accutase $^{\mathrm{TM}}$ (cat. No. A1110501), and 10× concentrated phosphate buffered saline (cat. No. BP399-1) were purchased from Thermo Fisher Scientific (Waltham, MA, USA).

Abelson murine leukemia virus transformed macrophage RAW 264.7 cells (ATCC ${ }^{\circledR}$ TIB-71) and Chinese Hamster Ovary CHO-K1 cells (ATCC ${ }^{\circledR}$ CCL-61) were purchased from ATCC. Two immortalized alveolar macrophage cell lines, B6 and ZK, were kindly provided by Prof. L. Kobzik (retired, Harvard TH Chan School of Public Health, Boston, MA, USA). B6 cells were derived from wild type (WT) C57BL/6 mice and ZK cells were derived from MARCO and SR-AI/II deficient (MS ${ }^{-/-}$) mice [22]. RAW 264.7 cells were cultured in DMEM base medium and WT B6 and MS ${ }^{-1}$ ZK cells were cultured in RPMI 1640 base medium. CHO cells stably transfected with full length mouse SR-A1 cDNA, termed CHO[mSR-AI] cells [23], were kindly provided by Prof. M. Krieger (Massachusetts Institute of Technology, Boston, MA, USA). As received $\mathrm{CHO}$ [mSR-AI] cells were cultured in selective medium containing $0.5 \mathrm{mg} / \mathrm{mL}$ of geneticin (G418) and single colonies were isolated by dilution plating. The surviving colonies were screened for high surface SR-A1 receptor expression by immuno-fluorescent FCyt, from which three sub-clones, termed $\mathrm{CHO}+$ mSRA1.A, CHO + mSRA1.B, and CHO + mSRA1.C were selected. $\mathrm{CHO}-\mathrm{K} 1$ and transfected $\mathrm{CHO}+$ mSRA1.A, CHO + mSRA1.B, and CHO + mSRA1.C cells were cultured in F-12K base medium. All regular culture media were supplemented with $1.5 \mathrm{mg} / \mathrm{mL}$ sodium bicarbonate, $10 \%(v / v)$ FBS, and $10 \mathrm{mM}$ HEPES buffer at $\mathrm{pH} 7.4$ for cells cultured in a $37^{\circ} \mathrm{C}$ incubator with $95 \%$ air and $5 \% \mathrm{CO}_{2}$. For cells incubated in a $4{ }^{\circ} \mathrm{C}$ incubator without $\mathrm{CO}_{2}$ supplement, no sodium bicarbonate was added to the media to maintain proper $\mathrm{pH}$. 
Table 1. Properties of pristine- (P-), amino-functionalized- (N-), and carboxylated-multi-walled carbon nanotubes (C-MWNT) powders and prepared Pluronic ${ }^{\circledR}$ F108-coated MWNT dispersions.

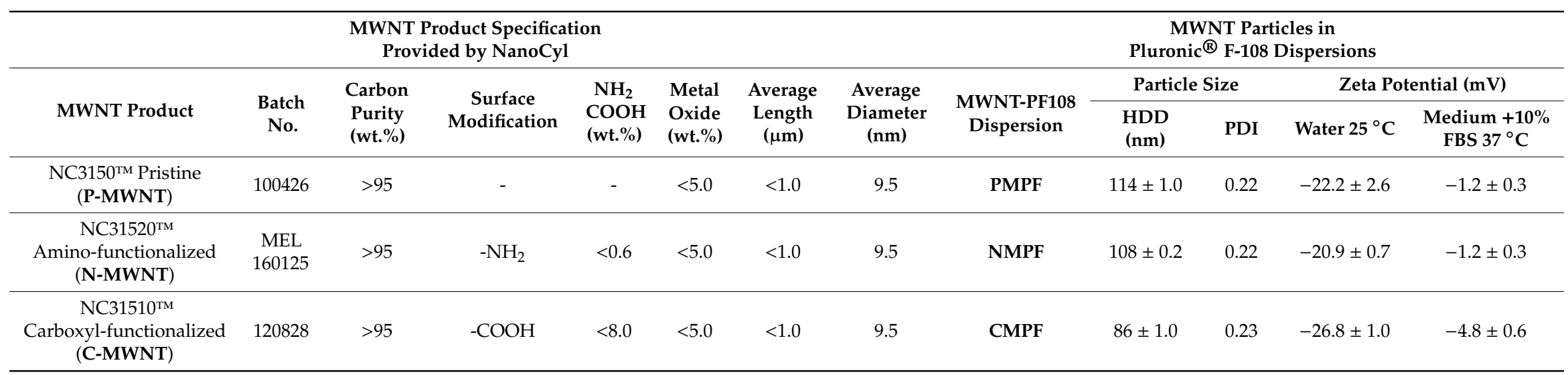




\subsection{Surface Expression of Class A Type 1 Scavenger Receptors $S R-A 1$ and MARCO}

Macrophage cell surface expression of SR-A1 and MARCO receptors was determined by a direct immunofluorescence FCyt assay. Macrophages cultured in 6-well plates at $37^{\circ} \mathrm{C}$ were washed three times with warm PBS to remove serum components present in the media and detached from the plate with gentle pipetting in enzyme-free PBS. Cells in suspension were washed twice with cold PBS and aliquots of $\sim 1 \times 10^{6}$ cells $/ 100 \mu \mathrm{L}$ in cold PBS were prepared. Macrophages often express Fc receptors on their surface that can bind to the Fc portion of a fluorescent reporter antibody. To block Fc receptors, $10 \mu \mathrm{g}$ of unlabeled mouse IgG was added and incubated with the cells for $15 \mathrm{~min}$ at $4{ }^{\circ} \mathrm{C}$. For immunostaining of surface SR-A1, $1 \mu \mathrm{g}$ of rat anti-mouse mSR-AI/MSR Alexa Fluor ${ }^{\circledR}$ 488-conjugated monoclonal antibody (R\&D Systems cat. No. FAB1797G) was added and incubated with the cells for $30 \mathrm{~min}$ at $4{ }^{\circ} \mathrm{C}$ in the dark. A duplicate cell aliquot was incubated with an isotype control rat IgG2b Alexa Fluor ${ }^{\circledR} 488$-conjugated monoclonal antibody (R\&D Systems cat. No. IC013G) to assess possible off-target staining by the anti-SR-A1 antibody. For immunostaining of surface MARCO receptors, a similar procedure was used but with a rat anti-mouse MARCO APC-conjugated monoclonal antibody (R\&D Systems cat. No. FAB2956A) and the corresponding APC-conjugated rat IgG1 isotype control antibody (R\&D Systems cat. No. IC005A). After incubation, unbound antibodies were washed away by centrifugation twice with $1 \mathrm{~mL}$ of cold FCyt staining buffer (R\&D Systems cat. No. FC001) at $1000 \times g$ for $8 \mathrm{~min}$. The washed cells were re-suspended in cold buffer and stored on ice in the dark. Flow cytometric analysis of 20,000 counts per sample was used to determine the presence or absence of specific fluorescent antibodies bound to SR-A1 or MARCO receptors on the cell surface. Cells with fluorescence intensity greater than the background isotype control were considered positive for the receptors.

\subsection{Accumulation of MWNTs in RAW 264.7, B6, ZK Macrophages and CHO Cell Lines}

The sodium dodecyl sulfate polyacrylamide gel electrophoresis (SDS-PAGE) procedure described in our previous work $[11,18,19]$ was used to determine the amount of MWNTs accumulated by cells after a $24 \mathrm{~h}$ exposure at $37^{\circ} \mathrm{C}$. Briefly, cells were seeded in 6-well plates in regular culture media overnight before incubating in either control media that contained no MWNTs or test media with $100 \mu \mathrm{g} / \mathrm{mL}$ of $\mathrm{P-}, \mathrm{N}-$, or C-MWNTs for $24 \mathrm{~h}$ at $37^{\circ} \mathrm{C}$. After incubation, cells were washed extensively with fresh medium and PBS and detached from culture plates with Accutase ${ }^{\mathrm{TM}}$ cell dissociation buffer. Cell numbers were determined using a Coulter Particle Counter, and MWNTs were extracted from cells and quantified using the SDS-PAGE method. The average amount of $\mathrm{P-}, \mathrm{N}-$, or C-MWNTs accumulated by the cell over a $24 \mathrm{~h}$ period was expressed as fg MWNT per cell.

\subsection{Apoptosis Assay}

The induction of apoptosis in RAW 264.7 cells was assessed after a $24 \mathrm{~h}$ incubation with media containing either $0.1 \mathrm{mM}$ PF108 alone, or $100 \mu \mathrm{g} / \mathrm{mL}$ of P-, N-, or C-MWNTs using an apoptosis detection kit (Invitrogen ${ }^{\mathrm{TM}}$ cat. No. V13242) with FITC-conjugated annexin V and propidium iodide (PI) duo fluorescent markers for FCyt analysis. A total of $3 \times 10^{4}$ RAW 264.7 cells/well were seeded in 24-well plates and incubated at $37^{\circ} \mathrm{C}$ overnight before the regular culture medium was replaced with freshly prepared control or test media and incubated for $24 \mathrm{~h}$. Untreated cells provided a negative control and cells treated with $100 \mathrm{nM}$ camptothecin (CPT) were used as a positive control for apoptosis. After the incubation, cells were washed 3 times with fresh medium and twice with PBS, then detached from culture plate by incubating in a PBS-based enzyme-free buffer for $5 \mathrm{~min}$ at $37^{\circ} \mathrm{C}$. Cells in suspension were washed, kept on ice, and stained with FITC-conjugated annexin V and PI for $15 \mathrm{~min}$ in the dark, according to the protocol provided by the kit. The externalization of phosphatidylserine in apoptotic cells was detected using green fluorescent-conjugated recombinant annexin $\mathrm{V}$ and the nuclei of dead or necrotic cells were detected using red fluorescent PI. After treatment with annexin V and PI, 10,000 cell counts per sample were analyzed using an FCyt cell analyzer (BD Accuri ${ }^{\mathrm{TM}}$ C6 Plus flow 
cytometer) where binding of annexin $\mathrm{V}$ was recorded in the green fluorescent channel and the binding of PI in the red fluorescent channel. Data were presented as dot plots, where green fluorescence for annexin V-FITC was plotted on the X-axis with a threshold set to $2 \times 10^{4}$, and red fluorescence for PI was plotted on the $Y$-axis with a threshold set to $1 \times 10^{4}$. In general, apoptotic cells show higher green fluorescence, necrotic cells show both higher green and higher red fluorescent signals, dead cells show high red but not green fluorescence, and viable cells show little or no fluorescence higher than background levels. The fractions of viable, apoptotic, necrotic, and dead cells in 10,000 counts analyzed per measurement were recorded.

\subsection{Crystal Violet Cell Proliferation Assay}

A standardized cytotoxicity assay based on cell proliferation described previously in our MWNT toxicity work [11,18] was used for cytotoxicity assessments with RAW 264.7 cells exposed to various MWNT types, doses, and exposure times. Briefly, $4 \times 10^{4}$ RAW 264.7 cells/well were seeded in 48-well plates and incubated at $37^{\circ} \mathrm{C}$ overnight before the regular cell culture media was replaced with freshly prepared control or test media for a $24 \mathrm{~h}$ exposure. $1 \times 10^{4}$ and $5 \times 10^{3}$ cells/well were seeded for longer exposures of $48 \mathrm{~h}$ and $72 \mathrm{~h}$, respectively. At the end of the incubation, cells were washed 3 times with fresh media, 2 times with PBS, and air-dried to fix the cells on the plate. Cell proliferation was determined using a crystal violet assay, as described in our previous work where it was also demonstrated that cell-associated CNTs do not interfere with the assay [24]. The proliferation of the untreated control cells was set to $100 \%$. IC50 values were estimated from a linear regression dose-effect trend line where the concentration of MWNT is needed to inhibit cell proliferation by $50 \%$.

\subsection{Colony Formation Efficiency (CFE) Assay}

A well-established CFE assay based on the ability of a cell to grow into a colony under the test condition [25] was used to assess the viability of RAW 264.7 cells exposed to different MWNT types and doses continuously for 8 day. 300 RAW 264.7 cells per well were seeded in 6-well plates, filled with $5 \mathrm{~mL} /$ well of control regular culture medium or test media that contained either $\mathrm{P}_{-}, \mathrm{N}_{-}$, or $\mathrm{C}_{-} \mathrm{MWNT}$ at a final MWNTs concentration of 25,50 , or $100 \mu \mathrm{g} / \mathrm{mL}$, and incubated at $37^{\circ} \mathrm{C}$ without disturbance to allow colony formation. At the end of the 8 day incubation, colonies were washed gently twice with fresh medium and twice with PBS, fixed to the plate by air-drying at room temperature, and stained with crystal violet $(0.1 \%$ w/v in $10 \%$ ethanol) for $15 \mathrm{~min}$ at room temperature. Excess unbound dye was removed by rinsing the plate with tap water gently. Images of the wells with stained colonies were acquired using a stereomicroscope (NikonSMZ745T with Nikon DS-Fi2 camera) with a $0.5 \times$ objective lens magnification. The number of colonies in a well was counted and colony formation efficiency (CFE) was defined as the ratio of the number of colonies formed over the number of cells seeded in the well. The CFE of the untreated control was set to 100\% and the IC50 value was estimated from a linear regression dose-effect trend line where the concentration of MWNT is needed to inhibit CFE by $50 \%$.

\subsection{Detection of Surface SR-A1 on RAW 264.7 Cells by Laser Scanning Confocal Fluorescence Microscopy (LSCFM)}

A total of $2 \times 10^{4}$ RAW 264.7 cells/well were seeded on glass coverslips in 4-well plates in regular culture media supplemented with $10 \%$ FBS for $24 \mathrm{~h}$ at $37^{\circ} \mathrm{C}$. The culture medium was replaced with freshly prepared control medium that contained no MWNTs or test media containing $100 \mu \mathrm{g} / \mathrm{mL}$ of $\mathrm{P}_{-}, \mathrm{N}-$, or $\mathrm{C}-\mathrm{MWNT}$ and incubated for $24 \mathrm{~h}$ at $37^{\circ} \mathrm{C}$. After incubation, control and test media were removed, cells were washed extensively, and chilled to $4{ }^{\circ} \mathrm{C}$ in media that contained no sodium bicarbonate. To block surface Fc receptors, $10 \mu \mathrm{g}$ of mouse IgG was added and incubated with the cells for $15 \mathrm{~min}$ at $4{ }^{\circ} \mathrm{C}$. For immunostaining of surface SR-A1, $1 \mu \mathrm{g}$ of rat anti-mouse mSR-AI/MSR Alexa Fluor ${ }^{\circledR}$ 488-conjugated monoclonal antibody (R\&D Systems cat. No. FAB1797G) was added and incubated with the cells for $30 \mathrm{~min}$ at $4{ }^{\circ} \mathrm{C}$ in the dark. After incubation, cells were washed to remove unbound antibodies and fixed with $4 \% w / v$ paraformaldehyde in PBS at room temperature for 
15 min. The nuclei were stained with Hoechst 33342 in PBS at room temperature for 5 min in the dark. The cells were then washed with PBS twice to remove excess Hoechst dye, rinsed in Milli-Q water, and the coverslips were mounted on glass slides in Fluoromount G.

Confocal fluorescence images were acquired at the Imaging and Histology Core Facility at UT Dallas using LSCFM (Olympus FV3000RS) with a 100× magnification UPLSAPO objective lens (NA 1.35) immersed in silicone oil. Blue fluorescence in the images denotes nuclei stained with Hoechst dye and was detected with Ex. $405 \mathrm{~nm}$ and Em. 430-470 nm wavelengths. Green fluorescence denoting surface SR-A1 was detected with Ex. $488 \mathrm{~nm}$ and Em. 500-600 nm wavelengths. At least 30 confocal stacks were acquired per field and Z-projected images were overlaid using ImageJ software. 3D rendering of cells was reconstructed from $\sim 30$ confocal images along the Z-axis and $360^{\circ}$ rotating images were recorded as video clips using ImageJ software.

\subsection{Phagocytosis of Polystyrene Beads Assessed by LSCFM, FCyt, and LSCRM}

A total of $2 \times 10^{4}$ cells/well were seeded in 4-well plates for FCyt analysis in regular culture media (DMEM for RAW 264.7 cells and RPMI 1640 for B6 and ZK cells) supplemented with 10\% FBS for $24 \mathrm{~h}$ at $37^{\circ} \mathrm{C}$. For LSCFM analysis, glass coverslips were inserted in the wells before $2 \times 10^{4}$ cells/well were seeded. The culture medium was replaced with either freshly prepared test media containing $100 \mu \mathrm{g} / \mathrm{mL}$ of $\mathrm{P}_{-}, \mathrm{N}-$, or C-MWNTs or control medium containing no MWNTs and incubated for $20 \mathrm{~h}$ at $37^{\circ} \mathrm{C}$. After incubation, control and test media were removed and cells were washed extensively with fresh medium and followed by a $1 \mathrm{~h}$ chase period in fresh culture medium at $37^{\circ} \mathrm{C}$. The medium was then replaced with fresh medium containing fluorescent polystyrene beads $(10 \mu \mathrm{g} / \mathrm{mL}$ for RAW 264.7 cells and $25 \mu \mathrm{g} / \mathrm{mL}$ for the B6 or ZK cells). The cells were exposed to the beads for $2 \mathrm{~h}$ at $37^{\circ} \mathrm{C}$. After the $2 \mathrm{~h}$ exposure, cells were washed extensively to remove excess beads in the media and chased in fresh medium at $37^{\circ} \mathrm{C}$ for phagocytosis of surface-bound but not yet internalized beads.

For LSCFM analysis, cells on coverslips were washed extensively, fixed with $4 \%$ w/v paraformaldehyde in PBS at room temperature for $15 \mathrm{~min}$, and washed twice with PBS. The nuclei were stained with Hoechst 33342 in PBS at room temperature for $5 \mathrm{~min}$ in the dark. The cells were washed with PBS twice to remove excess Hoechst dye, rinsed in Milli-Q water, and the coverslips were mounted on glass slides in Fluoromount G. The acquisition and processing of confocal fluorescence images of the cells were the same as those described in the previous section.

For FCyt analysis, cells were washed, detached from the well with Accumax ${ }^{\mathrm{TM}}$, and re-suspended in PBS. The cells in suspension were washed again with PBS and kept on ice in the dark. 10,000-20,000 cells per sample were analyzed using a flow cytometer where the green fluorescence intensity correlates to the number of phagocytosed beads in a cell. Cells with a green fluorescence intensity greater than the background auto-fluorescence intensity are considered positive for phagocytosed beads. The mean fluorescence index (MFI) of a sample, obtained by multiplying the \% of positive cells with phagocytosed beads and the mean fluorescence intensity, represents the phagocytic activity of the cells to take up polystyrene beads under the experimental conditions.

For laser scanning confocal Raman microscopy (LSCRM) analysis, RAW 264.7 cells were cultured on glass coverslips, incubated in control culture medium or in test medium containing $100 \mu \mathrm{g} / \mathrm{mL}$ C-MWNT for $2 \mathrm{~h}$ at $37^{\circ} \mathrm{C}$, washed extensively, chased in fresh culture for $30 \mathrm{~min}$, prior to exposure to $25 \mu \mathrm{g} / \mathrm{mL}$ of non-fluorescence and non-functionalized polystyrene beads for $2 \mathrm{~h}$ at $37^{\circ} \mathrm{C}$, washed again, then air-dried to prepare for Raman microscopy scanning. The polystyrene beads and C-MWNTs phagocytosed by the control or C-MWNT treated cells were detected using a WITec 500R LSCRM system and the acquired Raman scan images were processed using WITec Project 4 plus software (see further details in the SI Methods).

\subsection{Phagocytosis of Heat-Killed Fluorescent Bacteria Assessed by FCyt}

A total of $4 \times 10^{5}$ RAW 264.7 cells/well were seeded in 6-well plates in regular culture media supplemented with $10 \%$ FBS for $24 \mathrm{~h}$ at $37^{\circ} \mathrm{C}$. The culture medium was replaced with freshly prepared 
test media containing either $0.1 \mathrm{mM}$ PF108 alone, $100 \mu \mathrm{g} / \mathrm{mL}$ of P-, N-, or C-MWNTs, or control medium that contained no PF108 or MWNTs and incubated for $24 \mathrm{~h}$ at $37^{\circ} \mathrm{C}$. After incubation, control and test media were removed and cells were washed extensively with fresh medium and followed by a 1-h chase period in fresh culture medium at $37^{\circ} \mathrm{C}$. Cells were chilled to $4{ }^{\circ} \mathrm{C}$ and exposed to heat killed, Alexa Fluor ${ }^{\circledR} 488$-conjugated E. coli particles, at 30 E. coli particles per cell in fresh cold medium for $1 \mathrm{~h}$ at $4{ }^{\circ} \mathrm{C}$ in the dark. After the $1 \mathrm{~h}$ exposure, cells were washed extensively to remove unbound E. coli, chased in fresh medium at either $37^{\circ} \mathrm{C}$ or $4{ }^{\circ} \mathrm{C}$ for $1 \mathrm{~h}$, washed, and detached from the plate in enzyme-free buffer. Cells in suspension were washed twice in cold PBS and 20,000 cell counts per measurement were analyzed using a flow cytometer where the green fluorescence intensity correlates to the number of $E$. coli associated with a cell. Cells with a fluorescence intensity greater than the background auto-fluorescence intensity are considered positive for phagocytosed (for cells chased at $37^{\circ} \mathrm{C}$ ) or surface-bound (for cells kept at $4{ }^{\circ} \mathrm{C}$ ) E. coli.

\subsection{Distinguishing Extracellular from Internalized Florescent Markers by Trypan Blue Quenching}

A common fluorescence quenching technique with trypan blue (TB) [26,27] was used to distinguish internalized fluorescent-labeled particles from those attached to the cell surface, such as the Alexa Fluor $^{\circledR}$ 488-conjugated monoclonal antibody specific for SR-A1 or the heat killed E. coli particles used in the current study. Since trypan blue dye does not penetrate cell membranes, it may quench the green fluorescence of extracellular, i.e., free and surface-bound fluorescent-labeled particles, but has no effect on the fluorescence of particles internalized by the cell. To quantify the extent of fluorescence quenching by trypan blue, flow cytometric measurements of a sample were acquired as usual, in the absence of trypan blue, followed immediately by consecutive analysis in the presence of $0.1 \%$ trypan blue dye. The fluorescence intensity quenched by trypan blue is defined as the difference in fluorescence intensities measured in the absence $(-\mathrm{TB})$ and presence $(+\mathrm{TB})$ of the dye. The percent quenching by trypan blue was calculated as $[(-\mathrm{TB})-(+\mathrm{TB})] /(-\mathrm{TB})$, where the fluorescence intensity in the absence of dye was set to $100 \%$. A sample with high trypan blue quenching implies that the fluorescent markers reside on the cell surface. On the contrary, a sample with no fluorescence quenching by trypan blue suggests that the fluorescent markers were internalized by the cells.

\subsection{Uptake of Fluorescent and Non-Fluorescent OxLDL Assessed by FM, FCyt and Oil Red O (ORO) Stain}

A total of $2 \times 10^{4}$ cells/well were seeded in 4-well plates for FCyt analysis in regular culture media supplemented with $10 \%$ FBS for $24 \mathrm{~h}$ at $37^{\circ} \mathrm{C}$. For FM and ORO stain analysis, glass coverslips were inserted in the wells before cells were seeded. The culture medium was replaced with freshly prepared test media containing $0.1 \mathrm{mM}$ PF108 alone, $100 \mu \mathrm{g} / \mathrm{mL}$ of P-, N-, or C-MWNTs, or with fresh control medium containing no PF108 nor MWNTs and incubated for $20-24 \mathrm{~h}$ at $37^{\circ} \mathrm{C}$. After incubation, control and test media were removed and cells were washed extensively with fresh serum-free medium supplemented with $3 \%$ w/v BSA (SF + BSA medium) and followed by a $4 \mathrm{~h}$ serum starvation period at $37^{\circ} \mathrm{C}$.

For fluorescent oxLDL uptake assays, cells were incubated with fresh serum free (SF) + BSA medium containing DyLight ${ }^{\mathrm{TM}}$ 488-conjugated oxLDL (1:20 dilution for FM and 1:40 dilution for FCyt) for $2 \mathrm{~h}$ at $37^{\circ} \mathrm{C}$. Cells were then washed extensively to remove excess oxLDL in the media. For FM analysis, cells on coverslips were fixed with $4 \% w / v$ paraformaldehyde in PBS at room temperature for $15 \mathrm{~min}$, washed again with PBS, and the nuclei were stained with Hoechst 33342 in PBS at room temperature for $5 \mathrm{~min}$ in the dark before the coverslips were mounted on glass slides in Fluoromount G. Epi-fluorescence images were acquired using an inverted fluorescence microscope (Nikon Eclipse TE2000) with a 60× magnification oil immersion objective lens (NA 1.40). Blue color in the images denotes nuclei stained with Hoechst 33342 dye, detected with Ex. 365 nm and Em. 435-485 nm wavelengths. Green fluorescent oxLDL was detected with Ex. $475 \mathrm{~nm}$ and Em. 500-550 nm wavelengths. The Nikon NIS-Elements AR (v.4.40.00) software was used for image acquisition and includes a $2 \mathrm{D}$ deconvolution module used to reduce the imperfection of convolution 
on the fluorescence cell images. For FCyt analysis, cells were washed with PBS, detached from the well with Accumax ${ }^{\mathrm{TM}}$, washed again, and kept on ice in the dark. A total of 10,000 cells per sample were analyzed using a flow cytometer where the green fluorescence intensity correlates to the abundance of oxLDL in a cell. Cells with a green fluorescence intensity greater than the background auto-fluorescence intensity are considered positive for active oxLDL uptake. The mean fluorescence intensity of a sample represents the phagocytic activity of the cells to take up oxLDL under the experimental conditions.

To measure the uptake of non-fluorescent oxLDL using ORO staining, cells were incubated with fresh SF+BSA media with or without $25 \mu \mathrm{g} / \mathrm{mL}$ oxLDL for $16 \mathrm{~h}$ at $37^{\circ} \mathrm{C}$. After the incubation, cells were washed extensively and fixed with $4 \% w / v$ paraformaldehyde in PBS at room temperature for $15 \mathrm{~min}$. The oil droplets present in cells were stained with a freshly prepared $0.3 \% w / v$ ORO solution in $60 \%$ isopropanol for $15 \mathrm{~min}$ at room temperature. The ORO working solution was prepared by diluting a stock $0.5 \%$ w/v ORO in isopropanol solution (Sigma, cat. No. O1391) with MilliQ $\mathrm{H}_{2} \mathrm{O}$ at a 3:2 ratio. The solution was mixed, set for $10 \mathrm{~min}$, passed through a $0.22 \mu \mathrm{m}$ PVDF membrane syringe filter unit (MillexGV by Millipore, cat. No. SLGV033RS), and used within $30 \mathrm{~min}$. After staining with ORO, cells were washed extensively with water. To remove ORO stains on the glass coverslips and on the wells of culture plates, coverslips were removed from the wells carefully and dipped first in a beaker filled with clean water for $10 \mathrm{~s}$, then dipped in a second beaker filled with $50 \%$ isopropanol for $10 \mathrm{~s}$, quickly dipped in a third beaker filled with clean water for $10 \mathrm{~s}$, and transferred to wells filled with PBS in new 4-well plates. Bright-field images were acquired using a digital inverted microscope cell imaging system (EVOS FL AMEFC-4300) with a 40× magnification objective lens (NA 0.65), illuminated with an LED transmitted light at $60 \%$ intensity, and saved as 24-bit color TIFF files. To quantitate the amount of ORO associated with cells, the dye was eluted in $200 \mu \mathrm{L} /$ well of 100\% isopropanol (Sigma, cat. No. C-2432). The plates were placed on an orbital shaker for $15 \mathrm{~min}$ at room temperature and $150 \mu \mathrm{L}$ eluate from each well was transferred to a well in a 96-well plate. The absorbance at $510 \mathrm{~nm}$, corresponding to the ORO absorbance peak, was measured using a BioTek Synergy 2 Multi-Mode microplate reader (Winooski, VT, USA).

\section{Results}

\subsection{Surface SR-A1 and MARCO Receptor Expression in RAW 264.7, B6, and ZK Cells}

The mouse alveolar macrophage-derived cell line RAW 264.7 and two immortalized alveolar macrophage cell lines, B6 and ZK, were studied to evaluate the participation of SR-A receptors in MWNT uptake. B6 cells are derived from wild type (WT) C57BL/6 mice and ZK cells are from MARCO and SR-AI/II deficient ( $\mathrm{MS}^{-/-}$) mice [22]. The expression of surface SR-A1 and MARCO (SR-A6) receptors on RAW 264.7, WT B6, and $\mathrm{MS}^{-/}$- ZK cells was detected by immunofluorescence staining and determined quantitatively using FCyt, as described in the Methods section. Representative histograms of surface SR-A1 and MARCO receptor expression with RAW 264.7, B6, and ZK cells are shown in Figure 1A. Fluorescent staining with respective isotype control $\mathrm{mAbs}$ was included as a negative control. Both RAW 264.7 and WT B6 cells express high levels of surface SR-A1 whereas MS ${ }^{-/-} \mathrm{ZK}$ cells do not (Figure 1A, left panel). No relevant amount of MARCO receptors were detected on the surface of RAW 264.7, WT B6, or MS ${ }^{-/}$ZK cells (Figure 1A, right panel). For quantitative analysis, cells with fluorescence intensity greater than that of the isotype control are considered positive and the fraction of positive cells among 20,000 counts analyzed for each sample are plotted in Figure $1 \mathrm{~B}$. The results demonstrate that more than 90\% of RAW 264.7 and WT B6 cells express surface SR-A1 and only 2\% $\mathrm{MS}^{-1-} \mathrm{ZK}$ cells tested positive for surface SR-A1. The MFI is the average fluorescence signal from the cells analyzed and gives a quantitative comparison of the population fluorescence. The MFI for RAW 264.7 and WT B6 cells was $(102.4 \pm 4.2) \times 10^{3}$ and $(22.4 \pm 8.6) \times 10^{3}$, respectively. In contrast, $\mathrm{MS}^{-/-} \mathrm{ZK}^{-}$ cells express low surface SR-A1, evidenced by an MFI of $(1.6 \pm 1.5) \times 10^{3}$, barely exceeding the isotype control background level MFI of $(1.3 \pm 0.6) \times 10^{3}$. Unlike the SR-A1, the constitutive expression of the MARCO receptor appears to be low in all three alveolar macrophage cell lines tested (Figure 1B), 
with MFIs of $(1.2 \pm 0.7) \times 10^{3},(0.8 \pm 0.3) \times 10^{3}$, and $(0.7 \pm 0.3) \times 10^{3}$ for RAW 264.7, WT B6, and $\mathrm{MS}^{-/}$ZK mouse macrophages, respectively. This is consistent with prior studies indicating that RAW 264.7 cells express high levels of SR-A1 but not MARCO [15]. Note that the surface SR-A1 and MARCO receptor levels measured here using FCyt agree with PCR genotyping results reported previously by the Kobzik group [22]. Next, the amount of MWNTs accumulated by these cells was correlated with their expression of surface SR-A1 receptors.

(A) Representative Fluorescence Histograms
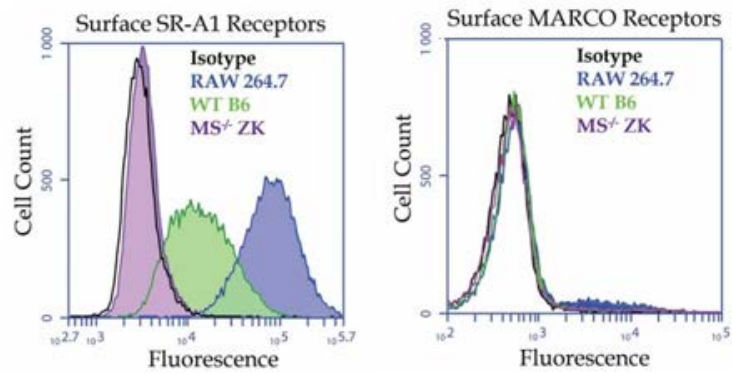

(B) \% Cells with Positive Fluorescence Intensity

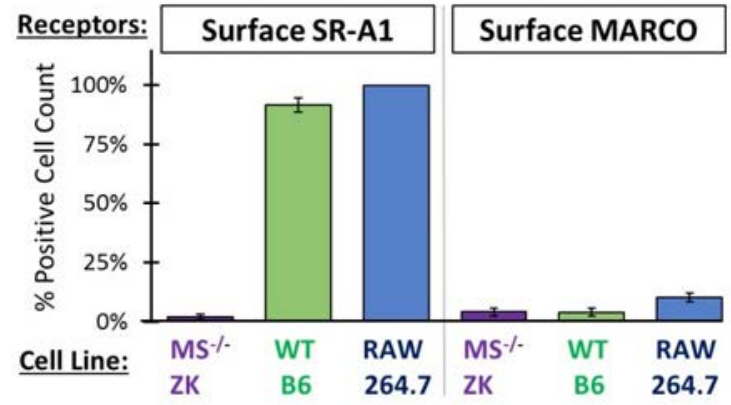

(C) 24h MWNT Accumulation

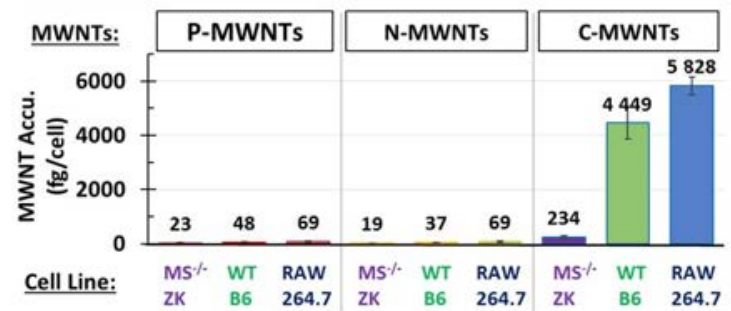

Figure 1. Surface SR-A1 receptor expression correlates with the accumulation of C-MWNTs by RAW 264.7, wild type (WT) B6, and MARCO and SR-AI/II deficient (MS) ${ }^{-/}$ZK murine alveolar macrophages. (A,B) Cell surface expression of SR-A1 and MARCO receptors was determined by direct immunofluorescence FCyt assays. Cells were prepared for cytometry as described in Methods using Alexa Fluor ${ }^{\circledR}$ 488-conjugated monoclonal anti-mouse SR-A1 or APC-conjugated monoclonal anti-mouse MARCO antibody. Cells with fluorescence intensity greater than the background isotype control were considered positive. (A) Representative fluorescence histograms of cells stained with anti-mouse SR-A1 (left panel) or with anti-MARCO (right panel), and corresponding isotype control antibodies. Black, isotype control; blue, RAW 264.7 cells; green, WT B6 cells; purple, $\mathrm{MS}^{-1-}$ ZK cells. (B) The fraction of positive cells out of a total 20,000 analyzed was expressed as the \% of cells positive for surface SR-A1 (left panel) or for surface MARCO (right panel) receptors. (C) The accumulation of $\mathrm{P}-, \mathrm{N}-$, or C-MWNTs by RAW 264.7, WT B6, and $\mathrm{MS}^{-/-}$ZK cells was determined after exposing cells to media containing $100 \mu \mathrm{g} / \mathrm{mL}$ of either $\mathrm{P}_{-}, \mathrm{N}-$, or $\mathrm{C}-\mathrm{MWNT}$ for $24 \mathrm{~h}$ at $37^{\circ} \mathrm{C}$ as described in Methods. Numbers above the bars are the average fg MWNTs per cell. Data in all panels of this figure are the average $\pm \mathrm{SD}$ of $\geq 3$ independent experiments. 


\subsection{Accumulation of MWNTs by RAW 264.7, WT B6, and MS ${ }^{-1-}$ ZK cells}

Results of our previous study on MWNT uptake by RAW 264.7 cells suggested that class A scavenger receptors might be involved in the 100-fold preferential uptake of C-MWNTs over P-MWNTs [11]. In the present study, in addition to P- and C-MWNTs, the interaction of N-MWNTs with macrophages was assessed to see if a surface functionalization other than oxidation affected uptake by cells. After a $24 \mathrm{~h}$ incubation in media containing $100 \mu \mathrm{g} / \mathrm{mL}$ of PF108-coated MWNTs, RAW 264.7 cells accumulated $69 \pm 18$ and $69 \pm 22 \mathrm{fg} /$ cell of P- and N-MWNTs, respectively, and accumulated $\sim 85$ fold more C-MWNTs at $5828 \pm 325 \mathrm{fg} /$ cell (Figure 1C). This is consistent with our previous results [11] and shows that N-MWNTs, like P-MWNTs, are not highly accumulated. Under the same experimental conditions as with RAW 264.7 cells, WT B6 cells also accumulated 100 fold more C-MWNTs than Por N-MWNTs, with an average of $48 \pm 25,37 \pm 8$, and 4,449 $\pm 591 \mathrm{fg} /$ cell of P-, N-, and C-MWNTs, respectively (Figure 1C). Notably, $\mathrm{MS}^{-/}$ZK cells that lack SR-A1 accumulated minimal $\mathrm{P}_{-}, \mathrm{N}-$, or C-MWNTs (Figure 1C). Thus, high C-MWNT accumulation correlates with high expression of surface SR-A1. Moreover, since RAW 264.7 and WT B6 cells express minimal MARCO receptors on their surface (Figure 1A,B), MARCO receptors apparently cannot be responsible for the high C-MWNTs uptake in these cells (Figure 1C). To further investigate the effect of SR-A1 on the accumulation of MWNTs, transfected $\mathrm{CHO}$ cells that stably express mouse SR-A1 were studied next.

\subsection{Selective High Uptake of C-MWNTs in CHO Cells Expressing SR-A1}

$\mathrm{CHO}$ cells stably transfected with full length mouse class A type I scavenger receptor cDNA, termed $\mathrm{CHO}[\mathrm{mSR}-\mathrm{AI}]$ cells, were kindly provided by Prof. M. Krieger [23]. As received CHO[mSR-AI] cells were re-selected in medium containing $0.5 \mathrm{mg} / \mathrm{mL}$ of geneticin (G418, Gibco) and single colonies were isolated by dilution plating. The surviving colonies were screened for high surface SR-A1 expression by immunofluorescence FCyt, from which three sub-clones, termed CHO + mSRA1.A, $\mathrm{CHO}+$ mSRA1.B, and CHO + mSRA1.C, were selected and used to investigate the involvement of SR-A1 on the accumulation of $\mathrm{P-}-\mathrm{N}-$, and $\mathrm{C}-\mathrm{MWNT}$ by $\mathrm{CHO}$ cells.

Immunofluorescence FCyt showed that these sub-clones of $\mathrm{CHO}[\mathrm{mSR}-\mathrm{AI}]$ cells stably expressed transfected murine surface SR-A1 at various levels, all greater than the background level of the non-transfected wild type CHO-K1 cells (Figure 2A). MFI comparisons indicated that surface SR-A1 levels were increased significantly over wild type $\mathrm{CHO}-\mathrm{K} 1$ cells, by $\sim$-fold for $\mathrm{CHO}+$ mSRA1.A and $\mathrm{CHO}+$ mSRA1.B cells, and by $\sim 3$-fold for $\mathrm{CHO}+$ mSRA1.C cells (Figure 2B).

To assess the contribution of SR-A1 to MWNT uptake, P-, N-, and C-MWNTs accumulated by wild type $\mathrm{CHO}-\mathrm{K} 1$ and transfected $\mathrm{CHO}+$ mSRA1.A, $\mathrm{CHO}+$ mSRA1.B, and CHO + mSRA1.C cells were determined under the same experimental conditions as described in the previous section for macrophages. Data in Figure 2C demonstrate an increased C-MWNT uptake in all three CHO $+\mathrm{mSR}-\mathrm{A} 1$ sub-clones, specifically, $358 \pm 211,812 \pm 221$, and $247 \pm 159 \mathrm{fg} / \mathrm{cell}$ C-MWNT for CHO + mSRA1.A, $\mathrm{CHO}+$ mSRA1.B, and CHO + mSRA1.C, respectively, which corresponds to 6-, 14-, and 4-fold increases relative to the $59 \pm 17 \mathrm{fg} / \mathrm{cell}$ for $\mathrm{CHO}-\mathrm{K} 1$ cells. The uptake of P- or N-MWNTs, however, remained minimal for all three $\mathrm{CHO}+\mathrm{mSR}-\mathrm{A} 1$ sub-clones, despite the higher SR-A1 expression levels compared to wild type CHO-K1 cells. Thus, the amount of surface SR-A1 correlates with the selective uptake of C-MWNT, but not P- or N-MWNT in CHO clones expressing SR-A1.

Altogether, the low C-MWNT uptake by cells that lack SR-A1 (MS ${ }^{-/-}$ZK macrophages, Figure 1) and the high uptake of C-MWNT by cells that over-express SR-A1 (CHO + mSRA1 clones, Figure 2) provide strong evidence that SR-A1 underlies the selective uptake of C-MWNTs in macrophages. To determine the potential physiological consequences of high-level accumulation of C-MWNT by macrophages, the cytotoxicity of PF108 alone, P-, N-, and C-MWNTs in RAW 264.7 cells was compared next using three different assays. 
(A) Representative Fluorescence Histograms (B) Mean Fluorescence Intensity
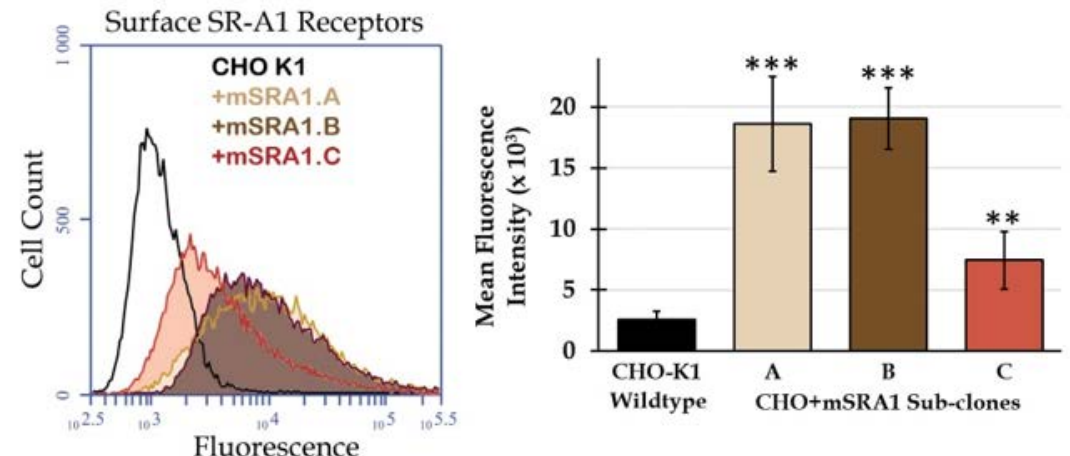

(C) $24 \mathrm{~h}$ MWNT Accumulation

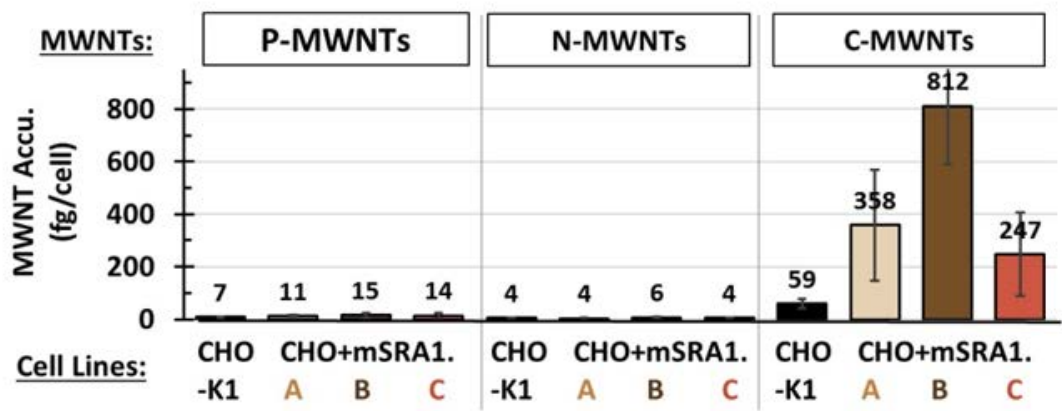

Figure 2. Surface SR-A1 receptor expression correlates with C-MWNT uptake by CHO-K1 and transfected $\mathrm{CHO}+$ mSRA1 clones. $(\mathbf{A}, \mathbf{B})$ Cell surface expression of SR-A1 receptors was determined by direct immunofluorescence FCyt assays. Cells detached from the culture vessel with enzyme-free buffer were incubated with mouse IgG to block Fc receptors before incubation with Alexa Fluor ${ }^{\circledR}$ 488-conjugated monoclonal anti-mouse mSR-A1 antibody. Alexa Fluor ${ }^{\circledR} 488$-conjugated rat IgG2b was used as isotype control. Cells with fluorescence intensity greater than the background isotype control were considered positive. The mean fluorescence intensity represents the surface expression level of SR-A1 receptors by the 20,000 cells analyzed. (A) Representative fluorescence histograms of cells stained with anti-mSR-A1. Black, untransfected CHO-K1 cells; beige, brown, and red, transfected $\mathrm{CHO}+$ mSRA1 sub-clones A, B, and C, respectively. (B) The surface SR-A1 receptor expression level represented as the mean fluorescence intensity of 20,000 cells analyzed per sample. Data are the mean \pm SD of triplicate measurements of each sample in $\geq 3$ independent experiments. ${ }^{* *}$ is for $p<0.0005$ and ${ }^{* * *}$ is for $p<0.00005$, compared to CHO-K1. (C) The accumulation of P-, N-, or C-MWNTs by untransfected CHO-K1 cells and transfected $\mathrm{CHO}+$ mSRA1 sub-clones $\mathrm{A}, \mathrm{B}$, and $\mathrm{C}$ was determined after exposing cells to media containing $100 \mu \mathrm{g} / \mathrm{mL}$ of $\mathrm{P}-, \mathrm{N}-$, or C-MWNT for $24 \mathrm{~h}$ at $37^{\circ} \mathrm{C}$. After incubation, the cells were washed, cell counts were determined using a Coulter Particle Counter, and MWNTs were extracted and quantified using the SDS-PAGE method. Numbers above the bars are the average $\mathrm{fg}$ MWNTs per cell. Data are the average \pm SD of $\geq 3$ independent experiments.

\subsection{The Effect of MWNT Accumulation on Apoptosis, Proliferation, and Colony Formation Efficiency}

The first set of experiments assessed the consequences of MWNT exposure on RAW 264.7 cell proliferation using a standardized crystal violet cell proliferation assay [11,24]. Specifically, the ability of cells to proliferate was determined as a function of $\mathrm{P}-, \mathrm{N}-$-, or C-MWNT concentration in the media, from 25 up to $200 \mu \mathrm{g} / \mathrm{mL}$, as well as a function of incubation time of 24,48, or $72 \mathrm{~h}$. Control cells were incubated in regular culture medium that contained no MWNTs or PF108 and their proliferation measured after incubation was set to $100 \%$.

After a $24 \mathrm{~h}$ incubation (Figure 3A), there was no significant decline in RAW 264.7 cell proliferation for cells with either P- or N-MWNTs at concentrations up to $200 \mu \mathrm{g} / \mathrm{mL}$, relative to the untreated controls. 
A slight reduction in proliferation was detected only for cells with C-MWNTs at concentrations of 150 and $200 \mu \mathrm{g} / \mathrm{mL}$. After a $48 \mathrm{~h}$ incubation (Figure 3B), again, no significant effects on cell proliferation were detected for cells with P- or N-MWNTs; however, a greater impact was observed for cells exposed to C-MWNTs, with an estimated IC50 of $120 \mu \mathrm{g} / \mathrm{mL}$. A longer incubation of $72 \mathrm{~h}$ with C-MWNTs aggravated the adverse effect on cell proliferation (Figure 3C), indicated by an IC50 of $80 \mu \mathrm{g} / \mathrm{mL}$. A $40-50 \%$ reduction in cell proliferation for cells with P- or N-MWNTs only became notable after a $72 \mathrm{~h}$ exposure and at $200 \mu \mathrm{g} / \mathrm{mL}$, the highest P- or N-MWNT concentration tested. These data indicate that the IC50 values for exposure to C-MWNTs decrease significantly with time. Therefore, we also studied the effect of MWNTs on RAW 264.7 cells in long-term colony formation assays.

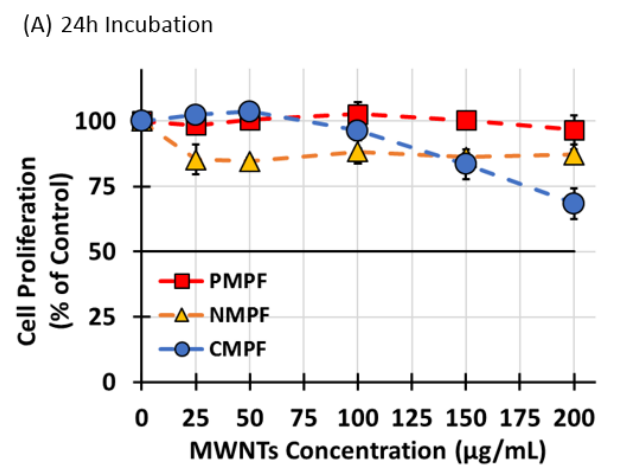

(B) $48 \mathrm{~h}$ Incubation

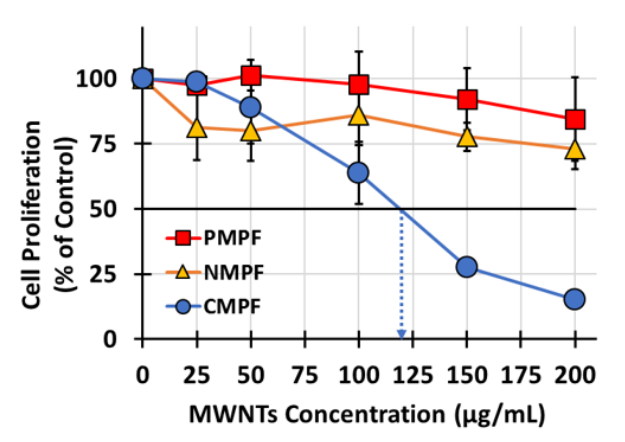

(C) $72 \mathrm{~h}$ Incubation

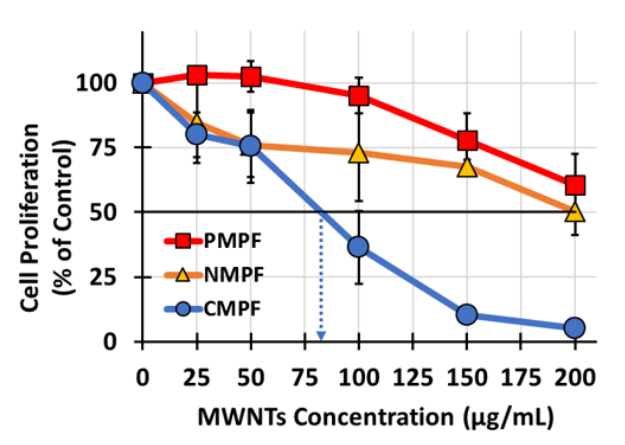

Figure 3. Effects of P-, N-, and C-MWNTs dose and exposure time on RAW 264.7 cell proliferation. RAW 264.7 cells in 48-well plates were incubated in media containing 25, 50, 100, 150, or $200 \mu \mathrm{g} / \mathrm{mL}$ of $\mathrm{P}-, \mathrm{N}-$, or C-MWNTs at $37^{\circ} \mathrm{C}$. Cells incubated in regular culture medium in the absence of MWNTs was the untreated control. IC50 values were estimated from a linear regression dose-effect trend line as the concentration of MWNTs needed to inhibit cell proliferation by $50 \%$. Cell proliferation after a (A) $24 \mathrm{~h}$, (B) $48 \mathrm{~h}$, or (C) $72 \mathrm{~h}$ exposure to MWNTs was determined by the crystal violet assay where the proliferation of control cells was set to $100 \%$. Dotted arrows indicate estimated IC50 values of 120 and $80 \mu \mathrm{g} / \mathrm{mL}$ for cells treated with C-MWNTs for 48 and $72 \mathrm{~h}$, respectively. Data are the average of quadruplicate measurements per sample in $\geq 3$ independent experiments \pm SEM. 
Colony formation assays (CFA), were performed next to assess the impact of various MWNTs on RAW 264.7 cells' survival upon long-term exposure. This assay tests the ability of single cells to proliferate and form a visible colony under the test condition [25] and has been previously used in studies with CNTs $[28,29]$. A total of 300 RAW 264.7 cells/well were seeded in a control of regular culture medium or in test media that contained either $\mathrm{P}_{-}, \mathrm{N}-$, or C-MWNTs at various MWNT concentrations up to $100 \mu \mathrm{g} / \mathrm{mL}$, and incubated without disturbance for 8 day to allow colony formation. Colonies were fixed, stained with crystal violet, imaged using a stereomicroscope, and counted.

Representative images of colonies of the untreated control group and cells incubated with $100 \mu \mathrm{g} / \mathrm{mL}$ P-, N-, or C-MWNTs are shown in Figure $4 \mathrm{~A}$. A total of $46 \pm 13 \%$ of seeded control RAW 264.7 cells formed colonies in 8 day whereas fewer colonies were produced from cells exposed to $100 \mu \mathrm{g} / \mathrm{mL}$ of P- or N-MWNTs. The efficiency of colony formation was near zero for C-MWNT-treated cells. The \% colony formation efficiency (CFE) was calculated for each sample, relative to the number of colonies produced by the untreated control set to $100 \%$. A dose-effect curve was plotted for each MWNT type in Figure 4B and demonstrates a dose-dependent decline for CFE. The IC50 values for cells exposed continuously to $\mathrm{P}_{-}, \mathrm{N}_{-}$, and C-MWNTs for 8 day were 79, 77, and $29 \mu \mathrm{g} / \mathrm{mL}$, respectively. The IC50 of $29 \mu \mathrm{g} / \mathrm{mL}$ for the effect of C-MWNT on viability suggests that even lower concentrations could have some adverse effects on cells after long-term exposure.

(A) Representative Images of Colonies on Culture Plates

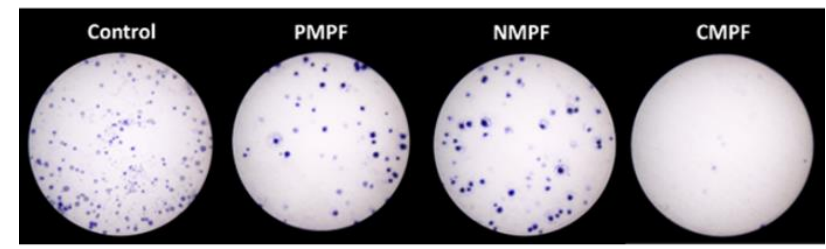

(B) CFE Dose-effect Curves

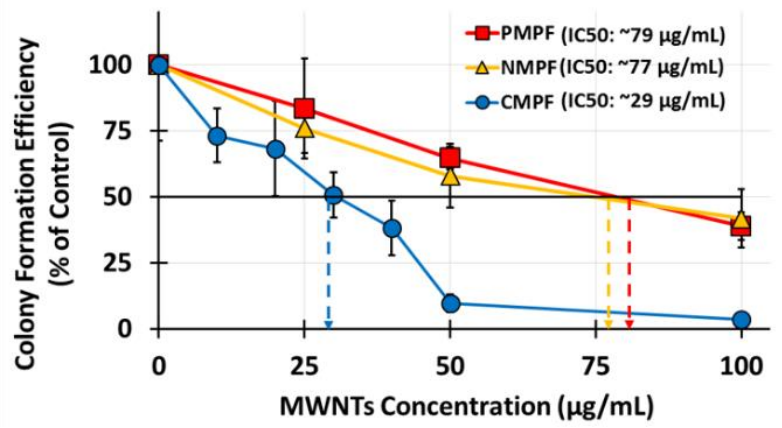

Figure 4. Colony formation efficiency (CFE) of RAW 264.7 cells after 8d of continuous exposure to $\mathrm{P}-, \mathrm{N}_{-}$, or C-MWNTs at various concentrations up to $100 \mu \mathrm{g} / \mathrm{mL}$. $300 \mathrm{RAW} 264.7$ cells were seeded in $35 \mathrm{~mm}$ culture plates with media containing various concentrations of $\mathrm{P}-, \mathrm{N}-$, or $\mathrm{C}-\mathrm{MWNTs}$ up to $100 \mu \mathrm{g} / \mathrm{mL}$ and incubated at $37^{\circ} \mathrm{C}$ in a $5 \% \mathrm{CO}_{2}$ incubator without disturbance for 8 day, then stained as described in Methods. CFE was defined as the ratio of the colony count over the seeded cell count in a plate. The concentration of MWNTs required to inhibit CFE by $50 \%$ (IC50) value was estimated from a linear regression dose-effect trend line. (A) Representative images of stained colonies in plates with control or cells treated with $100 \mu \mathrm{g} / \mathrm{mL}$ of P-, N-, or C-MWNTs. (B) CFE of RAW 264.7 cells incubated in media containing $\mathrm{P}-, \mathrm{N}-$, or $\mathrm{C}-\mathrm{MWNT}$ for 8 day at $37^{\circ} \mathrm{C}$, relative to untreated control where the CFE was set to $100 \%$. Dotted arrows indicate estimated IC50 values. Data are the average of 6 replicate plates per sample in $\geq 3$ independent experiments \pm SD.

Apoptosis was also assessed after a $24 \mathrm{~h}$ incubation with media containing either $0.1 \mathrm{mM}$ PF108 alone, or $100 \mu \mathrm{g} / \mathrm{mL}$ of $\mathrm{P}_{-}, \mathrm{N}-$, or C-MWNTs. Untreated cells provided a negative control and cells treated with $100 \mathrm{nM}$ CPT, a known DNA topoisomerase I inhibitor that causes DNA double-strand breaks [30], were used as positive controls for apoptosis. After the treatments, apoptotic, necrotic, 
and dead cells were detected using an apoptosis/dead cell detection kit with Annexin V-FITC and PI, according to the manufacturer's instruction. The \% of viable, apoptotic, necrotic, and dead cell fractions in 10,000 cell counts analyzed per sample were acquired using an FCyt cell analyzer. There was negligible necrosis and a background of $4 \%$ apoptosis in negative control cells. In CPT treated positive control cells, almost 53\% of the cells were apoptotic while necrosis was still low (Figure S1A). Only a low level of apoptosis (11.4-18.0\%) was detected in cells exposed to PF108 surfactant alone or to the various MWNTs. The mean \% apoptotic cell fractions are plotted as bar graphs in SI Figure S1B to further illustrate that regardless of high accumulation, C-MWNTs had only a mild apoptotic effect on cells in the first $24 \mathrm{~h}$ exposure. We next looked at what consequences C-MWNT accumulation via SR-A1 receptors might have on functions related to this receptor.

\subsection{Treatment of Cells with C-MWNTs, but Not P-or N-MWNTs, Depletes Surface SR-A1}

Phagocytosis is important for alveolar macrophages to remove foreign particles such as invading pathogens and dust from the lung. The interaction of C-MWNTs with SR-A1 receptors, and subsequent accumulation in cells, could impair macrophage phagocytic activity. The experiments described in the following sections address: (1) whether the accumulation of C-MWNTs via SR-A1 depletes this important receptor from the cell surface; and (2) whether C-MWNT accumulation impairs the ability of cells to phagocytose ligands, such as polystyrene beads, E. coli, and oxidized LDL (oxLDL) that are known to interact with SR-A1 [22,31-34].

Two approaches were used to assess the effects of MWNTs on surface SR-A1 levels in RAW 264.7 cells, a qualitative immunofluorescence microscopy (IFM) assay and a quantitative FCyt assay. The timeline schematic in Figure 5A presents the key steps used to prepare samples for the IFM and FCyt experiments (full details described in the Methods section). Briefly, RAW 264.7 cells were incubated in control medium that contained no PF108 or MWNTs or in test media that contained $0.1 \mathrm{mM}$ PF108 alone or $100 \mu \mathrm{g} / \mathrm{mL}$ of $\mathrm{P}_{-}, \mathrm{N}-$, or C-MWNTs at $37^{\circ} \mathrm{C}$ for $24 \mathrm{~h}$, washed extensively, chased in fresh medium for $1 \mathrm{~h}$ at $37^{\circ} \mathrm{C}$, and then chilled to $4{ }^{\circ} \mathrm{C}$. Half of the cells were incubated with a green Alexa Fluor ${ }^{\circledR} 488$-conjugated mAb specific for mouse SR-A1 and the other half with an Alexa Fluor ${ }^{\circledR}$ 488-conjugated isotype control $\mathrm{mAb}$ as a negative control, at $4{ }^{\circ} \mathrm{C}$ for $30 \mathrm{~min}$ in the dark. The cells were then prepared either for IFM or FCyt as described in Methods.

Representative LSCFM images of cells stained with Alexa Fluor ${ }^{\circledR}$ 488-conjugated mAbs for SR-A1 and Hoechst dye for the nucleus are shown in Figure 5B. Green fluorescence marking surface SR-A1 was in punctate spots, noted previously and attributed to the localization of SR-A1 in lipid rafts on the cell surface [33]. After C-MWNT treatment, considerably fewer green punctate spots were observed and the spots appeared mainly at cell margins where the cell membrane was attached to the glass coverslip. The untreated control cells appeared to have abundant SR-A1 stains while cells treated with P- and N-MWNTs had slightly less SR-A1 on their surface (Figure 5B). See SI Figure S2 for $360^{\circ}$ rotating video clips of representative control and C-MWNT-treated RAW 264.7 cells stained with green fluorescent mAbs against surface SR-A1. None of the cells stained with isotype control mAbs emitted detectable green fluorescence signal, which indicates negligible background fluorescence in this assay (data not shown). These data suggested that SR-A1 might be depleted from the cell surface in RAW 264.7 cells pre-exposed to C-MWNTs, and this was next tested by quantitative FCyt assay.

Cells with a green fluorescence intensity $>1 \times 10^{4}$ in the FCyt assay were considered positive for surface SR-A1. Results (Figure 5C, left panel) indicated that $\geq 97 \%$ of RAW 264.7 cells tested positive for surface SR-A1, regardless of any pre-treatment or not. However, as previously noticed in the LSCFM images (Figure 5B), not all SR-A1 positive cells express the same level of surface SR-A1 (Figure 5C right panel). Exposing cells to PF108 alone for $24 \mathrm{~h}$ had no effects on their surface SR-A1 expression. A mild reduction in surface SR-A1 expression, of $7 \%$ and $16 \%$, was detected in cells pre-treated with either Por N-MWNTs, respectively, compared to the untreated control cells. A 40\% reduction of surface SR-A1 was detected in RAW 264.7 cells pre-treated with $100 \mu \mathrm{g} / \mathrm{mL}$ C-MWNTs for $24 \mathrm{~h}$ (Figure 5C, right panel). One interpretation of these data is that notable amounts of surface SR-A1 are depleted from the 
cell surface upon exposure to C-MWNTs over time. Alternatively, it is possible that cell-associated MWNTs interfere with quantifying surface SR-A1, by quenching the antibody fluorophore signal or by preventing the binding of the reporter antibody in the FCyt experiments. To assess the alternative possibilities, further control experiments were performed, as described next.

(A) Experimental Scheme

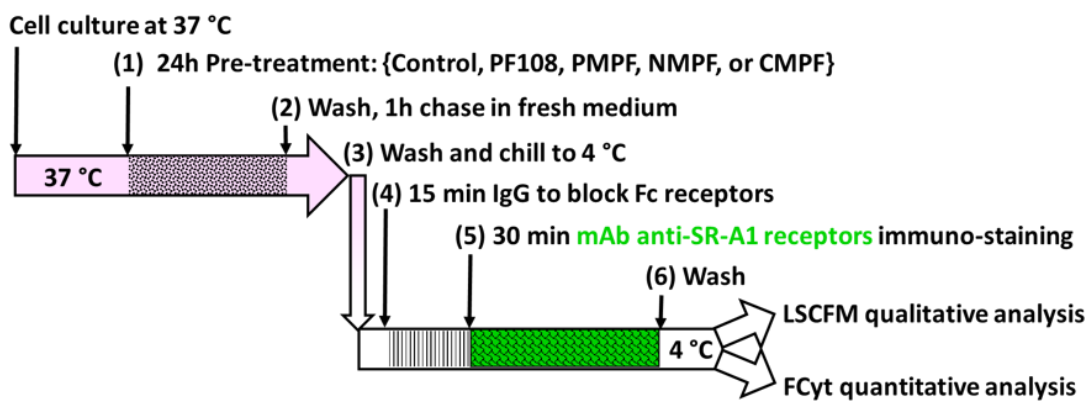

(B) LSCFM Images of RAW 264.7 Cells with Surface SR-A1 Receptors

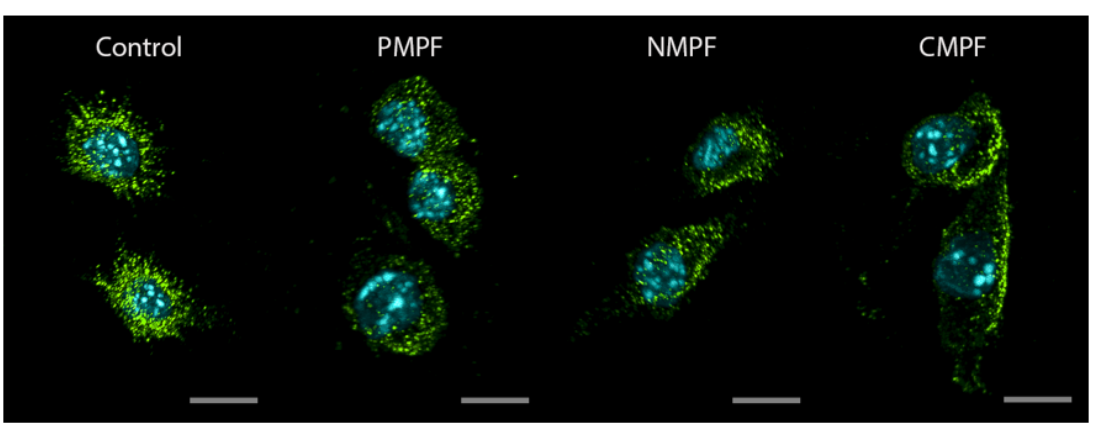

(C) FCyt for Surface SR-A1 Receptors
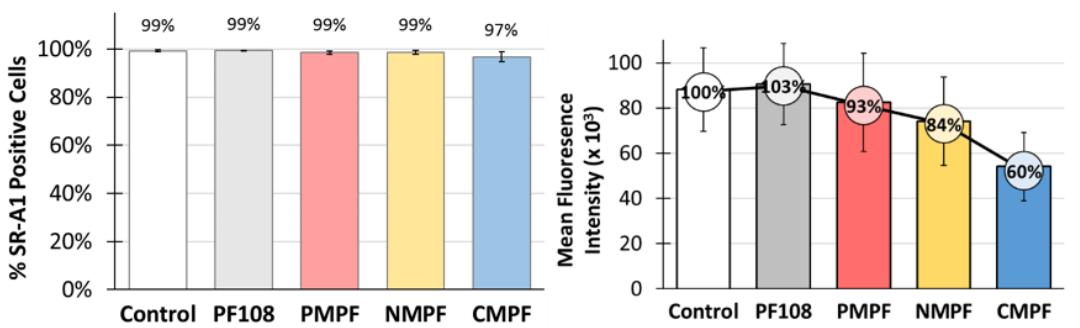

Figure 5. Effects of MWNT accumulation on surface SR-A1 receptor expression in RAW 264.7 cells. RAW 264.7 cells were incubated in media containing $0.1 \mathrm{mM}$ PF108 alone or $100 \mu \mathrm{g} / \mathrm{mL}$ of P-, N-, or CMPF at $37^{\circ} \mathrm{C}$ for $24 \mathrm{~h}$. Cells incubated in regular culture medium in the absence of PF108 and MWNTs are the untreated control. Cells were washed and chased in fresh medium at $37^{\circ} \mathrm{C}$ for $1 \mathrm{~h}$ to promote internalization of MWNTs that may have been on the cell surface. SR-A1 on the cell surface was immunologically detected by either FCyt or LSCFM as described in Methods. Briefly, cells were detached from culture plates with enzyme-free buffer, washed, chilled on ice, and appropriate antibodies were added to cells at $4{ }^{\circ} \mathrm{C}$ to prevent internalization of receptors or ligands. (A) The timeline scheme outlines the key experimental steps. (B) Representative Laser Scanning Confocal Fluorescence Microscopy (LSCFM) images of untreated control and MWNT-treated cells. Blue fluorescence is emitted from Hoechst 33342 stained nucleus and green fluorescence is from Alexa Fluor ${ }^{\circledR}$ 488-conjugated SR-A1 receptors. Scale bars are $10 \mu \mathrm{m}$. (C) The fraction of positive cells out of a total 20,000 analyzed by flow cytometry was expressed as the \% of positive for surface SR-A1 (left panel). The surface SR-A1 receptor expression level is represented as the mean fluorescence intensity of 20,000 cells analyzed per sample (right panel). Percent values inside circles are the mean fluorescence intensity relative to untreated control where the surface SR-A1 receptor level was set to $100 \%$. Data are the mean \pm SD of triplicate measurements per sample in $\geq 3$ independent experiments. 


\subsection{MWNTs Do Not Interfere with Immunofluorescence FCyt Assays for Surface SR-A1}

To test whether surface-bound MWNTs interfered with the detection of SR-A1 receptors, RAW 264.7 cells were exposed to MWNTs at $4{ }^{\circ} \mathrm{C}$ for $1 \mathrm{~h}$, washed to remove unbound MWNTs, and incubated in fresh medium for $1 \mathrm{~h}$ at $4{ }^{\circ} \mathrm{C}$. Control cells were kept in medium in the absence of MWNTs at $4{ }^{\circ} \mathrm{C}$. Cells were immuno-stained with fluorescent-conjugated monoclonal anti-SR-A1 antibodies and analyzed for the presence of surface-SR-A1 by FCyt (See SI Figure S3A for a timeline of the treatment). The fluorescent signal in cells treated with MWNTs at $4{ }^{\circ} \mathrm{C}$ was compared with the signal from untreated control cells. Interference would be indicated if the signal is attenuated by surface bound MWNTs in the MWNT-treated cells. There was no effect of exposing cells to any type of MWNT at $4{ }^{\circ} \mathrm{C}$ on the mean fluorescence intensity of the anti-SR-A1 antibody compared to the untreated control (SI Figure S3B, left side).

Furthermore, to determine whether internalized MWNTs could interfere with the detection of surface anti-SR-A1 immunofluorescence, cells were exposed to MWNTs at $4{ }^{\circ} \mathrm{C}$ for $1 \mathrm{~h}$ to allow binding, washed to remove unbound material, and then chased at $37^{\circ} \mathrm{C}$ for $1 \mathrm{~h}$ to permit internalization (see SI Figure S3A). The results in SI Figure S3B, right side, indicate that the internalized MWNTs did not reduce the mean fluorescent signal of the anti-SR-A1 antibody compared to the control. Altogether, these data suggest that neither surface-bound nor internalized MWNTs block the binding of anti-SR-A1 antibody or quench the fluorescent signals of the antibody in the FCyt assay. Thus, the observed $40 \%$ reduction of surface SR-A1 in RAW 264.7 cells exposed to C-MWNTs for $24 \mathrm{~h}$ is most likely due to a depletion of the SR-A1 receptors from the cell surface over time.

Considering that the accumulation of C-MWNTs by RAW 264.7 cells appears to reduce the expression of SR-A1 on the cell surface, there should be a corresponding effect on the uptake of other SR-A1 receptor ligands. To test this, we next compared the uptake of polystyrene beads, E. coli, and oxLDL by untreated control and MWNT-treated RAW 264.7 cells.

\subsection{Accumulation of C-MWNTs, but Not P- or N-MWNTs, Reduces Uptake of Polystyrene Beads}

Polystyrene beads are negatively charged and are known to bind SR-A1 [22,33,34]. To check the phagocytic ability of RAW 264.7 cells after exposure to different MWNTs, polystyrene beads with internally bound green fluorophores and a nominal diameter of $0.9 \mu \mathrm{m}$ were used as phagocytic markers. RAW 264.7 cells were pre-incubated with $100 \mu \mathrm{g} / \mathrm{mL} \mathrm{P-,} \mathrm{N-,} \mathrm{or} \mathrm{C-MWNTs,} \mathrm{or} \mathrm{with} 0.1 \mathrm{mM}$ PF108 alone at $37^{\circ} \mathrm{C}$ for $20 \mathrm{~h}$, washed, and then exposed to $10 \mu \mathrm{g} / \mathrm{mL}$ fluorescent polystyrene beads for $2 \mathrm{~h}$ at $37^{\circ} \mathrm{C}$, followed by a 1 -h chase at $37^{\circ} \mathrm{C}$ in the dark (Figure $6 \mathrm{~A}$ ). The presence of the beads in cells was determined by qualitative assessment using LSCFM and by quantitative FCyt measurement. Representative confocal fluorescence images of untreated control cells and MWNT-treated cells (Figure 6B) visually demonstrate a reduced number of beads in C-MWNT-treated RAW 264.7 cells, whereas cells treated with P- or N-MWNTs have a sparingly reduced number of beads, relative to that of the control cells.

The quantitative results of FCyt analysis (Figure 6C) revealed that the untreated control and cells exposed to either PF108 alone, P-, or N-MWNTs all have high levels of phagocytosed beads, with MFIs of $2.6 \times 10^{6}, 2.1 \times 10^{6}, 2.0 \times 10^{6}$, and $2.1 \times 10^{6}$, respectively, indicative of robust phagocytic activity. On the contrary, cells treated with C-MWNTs displayed a significantly reduced level of phagocytosed polystyrene beads, evidenced by a low MFI of $1.0 \times 10^{6}, \sim 40 \%$ that of the control cells (Figure $6 \mathrm{C}$ ). These data are consistent with the qualitative observations with LSCFM (Figure 6B and SI Figure S4) and support the idea that the accumulation of C-MWNTs impairs the subsequent uptake of a SR-A1 receptor ligand. Note that in Figure 6B there appears to be fewer, but bright, beads within C-MWNT treated cells, suggesting that quenching is not responsible for the reduced fluorescence signal in cytometry experiments with C-MWNT treated cells. 


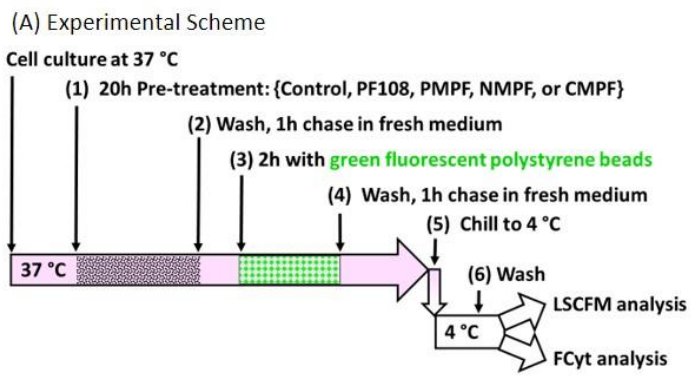

(B) LSCFM Images of RAW 264.7 Cells with Beads

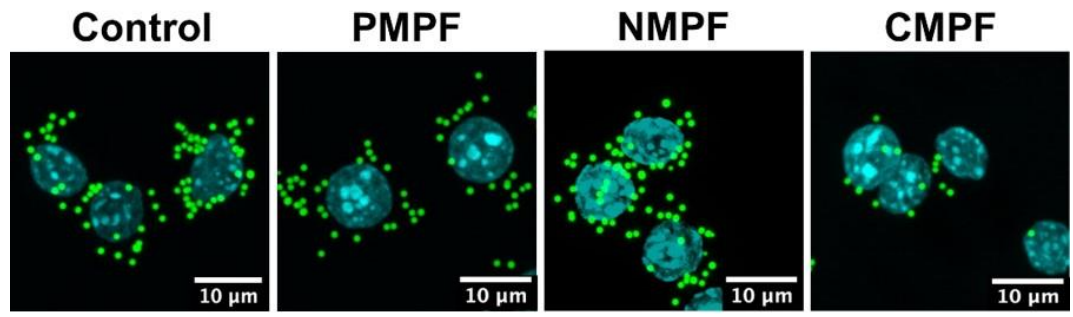

(C) Uptake of Beads by RAW 264.7 Cells

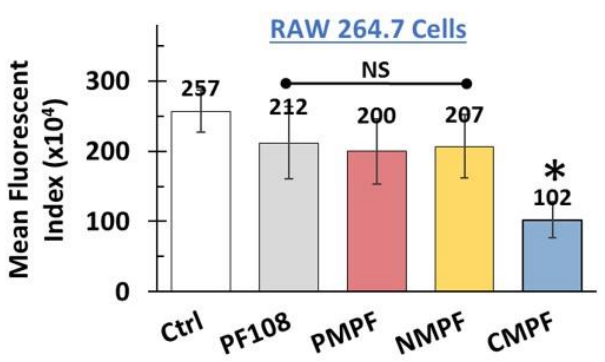

(D) Uptake of Beads by WT B6 and MS $\%$ ZK Cells

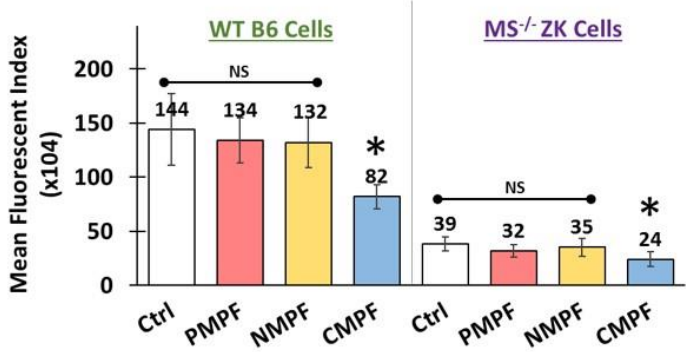

Figure 6. Effects of MWNT accumulation on subsequent phagocytosis of polystyrene beads in murine alveolar macrophage cell lines. RAW 264.7, wild type B6, and $\mathrm{MS}^{-1-} \mathrm{ZK}$ cells were incubated in media containing $100 \mu \mathrm{g} / \mathrm{mL}$ of $\mathrm{P}_{-}, \mathrm{N}-$, or C-MWNTs at $37^{\circ} \mathrm{C}$ for $20 \mathrm{~h}$. Untreated control cells were incubated in regular culture medium in the absence of PF108 surfactant or MWNTs. Cells were prepared for LSCFM or FCyt as described in Methods. (A) The timeline scheme outlines the key experimental steps. (B) Representative LSCFM images of untreated control and MWNT-treated cells. Blue fluorescence is emitted from Hoechst 33342 stained nuclei and green fluorescence is from phagocytosed polystyrene beads. (C) Mean fluorescence index of RAW 264.7 control, cells pre-treated with $0.1 \mathrm{mM}$ PF108 alone, or with $100 \mu \mathrm{g} / \mathrm{mL}$ of P-, N-, or C-MWNTs. (D) Mean fluorescence index of WT B6 (left panel) and MS $^{-/-}$ZK (right panel) controls and cells pre-treated with $100 \mu \mathrm{g} / \mathrm{mL}$ of $\mathrm{P}_{-}, \mathrm{N}-$-, or C-MWNTs. Data are the mean \pm SD of duplicate measurements per sample in $\geq 3$ independent experiments. NS is for no significant differences $(p>0.05)$ among test groups, ${ }^{*}$ is for $p<0.0005$ against control.

The possibility that polystyrene beads and PF108-coated C-MWNTs are internalized by the same receptor predicts that they might sometimes both end up within the same phagolysosomes in cells exposed to both ligands. To test this prediction, we used LSCRM to determine whether the distinct 
Raman signals of polystyrene beads and C-MWNTs co-localized. In LSCRM, a laser scans the cells attached on a coverslip and briefly pauses at each pixel to collect a complete Raman scattering spectrum of the sample, one spectrum per pixel. The scattering signals of C-MWNTs and polystyrene beads in different regions can be extracted, separated, assigned colors, and overlaid to see if they overlap. However, since our results suggest that C-MWNTs and polystyrene beads may use the same receptor, the cells were not simultaneously exposed to both to avoid competition; rather, they were first exposed to C-MWNTs for $2 \mathrm{~h}$, washed, then exposed to beads for $2 \mathrm{~h}$. The cells were then fixed and analyzed by LSCRM as described in the Supplemental Information methods. The Raman signal (red) of cells exposed to beads alone for $2 \mathrm{~h}$ mapped to the position of beads seen by bright field microscopy (SI Figure S6, top, left and right). In cells first treated with C-MWNTs for $2 \mathrm{~h}$, washed, then exposed to beads for $2 \mathrm{~h}$, the location of C-MWNTs (green) was visible, as were structures that were yellow, indicating colocalization of beads and C-MWNTs (SI Figure S6, bottom, left and right). The colocalization is partial, as expected because the cells were exposed to the two ligands at separate times. These data provide evidence independent of fluorescence methods that C-MWNTs are internalized and appear with beads in structures that have the expected perinuclear distribution of phagolysosomes.

The effect of MWNTs on the uptake of polystyrene beads was also tested with wild type B6 macrophages, which have SR-A1, and with $\mathrm{MS}^{-1-} \mathrm{ZK}$ cells, which lack SR-A1. Wild type B6 and $\mathrm{MS}^{-/-}$ZK cells pre-incubated with $100 \mu \mathrm{g} / \mathrm{mL} \mathrm{P-}, \mathrm{N}-$, or C-MWNTs at $37^{\circ} \mathrm{C}$ for $20 \mathrm{~h}$ were washed, chased in fresh medium for $1 \mathrm{~h}$, incubated with $25 \mu \mathrm{g} / \mathrm{mL}$ fluorescent polystyrene beads for $2 \mathrm{~h}$ at $37^{\circ} \mathrm{C}$, and washed again prior to FCyt analysis for phagocytosed beads in the cells. Quantitative FCyt results (Figure 6D, left panel) showed that untreated control WT B6 cells and those treated with Pand N-MWNTs have similar phagocytic function and internalized a large number of beads within $2 \mathrm{~h}$ of exposure at $37^{\circ} \mathrm{C}$, indicated by their MFI values of $1.4 \times 10^{6}, 1.3 \times 10^{6}$, and $1.3 \times 10^{6}$, respectively. WT B6 cells treated with C-MWNT, in contrast, displayed a $43 \%$ reduction in the uptake of polystyrene beads (MFI $8.2 \times 10^{5}$ ), compared to the control B6 cells, consistent with the idea that accumulation of C-MWNTs via SR-A1 impairs subsequent uptake of polystyrene beads by WT B6 cells. Unlike the RAW 264.7 or the WT B6 cells, untreated $\mathrm{MS}^{-/-}$ZK cells tested under the same experimental conditions show minimal uptake of polystyrene beads (MFI $3.9 \times 10^{5}$ ) by the untreated control ZK cells, verifying that SR-A1 are essential for the phagocytosis of polystyrene beads (Figure $6 \mathrm{D}$, right panel). $\mathrm{MS}^{-1-} \mathrm{ZK}$ cells treated with P-, N-, or C-MWNTs also showed minimal uptake of polystyrene bead (MFIs $3.2 \times 10^{5}$, $3.5 \times 10^{5}$, and $2.4 \times 10^{5}$, respectively).

Replicate experiments of WT B6 and SR-A1-deficient $\mathrm{MS}^{-1-} \mathrm{ZK}$ cells were analyzed using LSCFM. SI Figure S4 displays representative confocal fluorescence images of B6 and ZK cells with phagocytosed green fluorescent beads and nuclei stained with blue fluorescent Hoechst 33342 dye. The qualitative visual assessment of WT B6 and MS ${ }^{-1-}$ ZK cells using LSCFM (SI Figure S4) confirms the quantitative FCyt results (Figure 6D) for these cells under the same experimental conditions. Altogether, the attenuated uptake of an SR-A1 ligand by cells pre-treated with C-MWNTs correlates well with the observation that C-MWNT accumulation appears to deplete SR-A1 from the cell surface. This correlation was further tested using a bacterial SR-A1 ligand.

\subsection{Accumulation of C-MWNTs, but Not P-or N-MWNTs, Impairs Subsequent E. coli Uptake}

Alveolar macrophages play a key role in host defense against invading pathogens where SR-A1 is critical for bacteria clearance $[31,35]$. In the following experiments, the potential adverse impacts of C-MWNT accumulation in alveolar macrophage-derived RAW 264.7 cells on E. coli clearance were investigated. A schematic of the experimental approach is shown in Figure 7A. Briefly, RAW 264.7 cells were incubated with $100 \mu \mathrm{g} / \mathrm{mL}$ of the indicated MWNTs for $24 \mathrm{~h}$ at $37^{\circ} \mathrm{C}$, chased for $1 \mathrm{~h}$ at $37^{\circ} \mathrm{C}$ and then exposed to heat-killed, green fluorescent-conjugated E. coli particles with a multiplicity of infection (MOI) of 30 at $4{ }^{\circ} \mathrm{C}$ for $1 \mathrm{~h}$ in the dark. Cells were washed to remove unbound E. coli particles, placed in fresh medium at $37^{\circ} \mathrm{C}$ for $1 \mathrm{~h}$ to allow phagocytosis, washed, and analyzed for $E$. coli inside the cells by FCyt. To verify that the fluorescence measured under such conditions was from internalized E. coli, 
cells were treated with $\mathrm{TB}$, which is known to quench extracellular fluorescent signals but has no effect on internalized fluorescence $[26,27]$. To confirm that TB was an effective quencher of fluorescent E. coli, the bacteria were directly exposed to TB in solution and the quenching was assessed by cytometry. The results of this control experiment indicated that the fluorescent signal was quenched by $94 \%$, as shown in SI Figure S5.

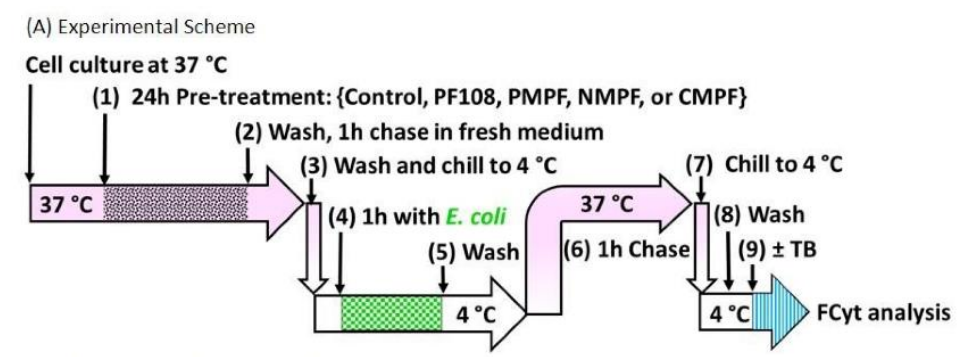

(B) Phagocytosed E. coli Particles

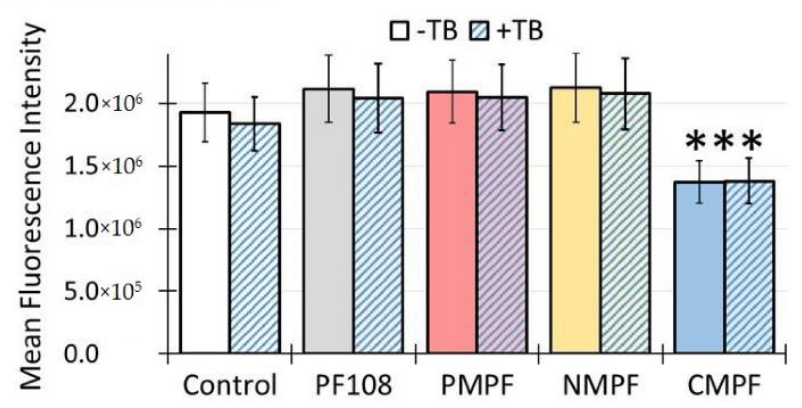

Figure 7. A 24 h exposure of RAW 264.7 cells to C-MWNTs, but not P- or N-MWNTs, impairs subsequent phagocytosis of E. coli. RAW 264.7 cells were incubated in media containing $100 \mu \mathrm{g} / \mathrm{mL}$ of $\mathrm{P}_{-}, \mathrm{N}_{-}$, or C-MWNTs, or $0.1 \mathrm{mM}$ PF108 alone at $37^{\circ} \mathrm{C}$ for $24 \mathrm{~h}$. The cells were chilled to $4{ }^{\circ} \mathrm{C}$ and exposed to heat-killed Alexa Fluor ${ }^{\circledR} 488$-conjugated E. coli, at 30 E. coli particles per cell, for $1 \mathrm{~h}$ at $4{ }^{\circ} \mathrm{C}$, washed, chased for $1 \mathrm{~h}$ at $37^{\circ} \mathrm{C}$ to allow phagocytosis, washed again, and analyzed by FCyt as described in Methods. Cells with a fluorescence intensity greater than the background auto-fluorescence were considered positive for phagocytosed E. coli. Flow cytometric measurements of a sample were followed immediately by consecutive analysis in the presence of $0.1 \%$ trypan blue dye, as described in Methods. (A) The timeline scheme outlines the key experimental steps. (B) E. coli phagocytosed by untreated control, PF108-treated, MWNT-treated cells. Mean fluorescence intensity was measured in the absence $(-\mathrm{TB})$ and subsequent presence (+TB) of $0.1 \%$ trypan blue. ${ }^{* * *}$ is for $p<0.0005$. Data are the mean \pm SD of triplicate measurements per sample in $\geq 3$ independent experiments.

The results in Figure 7B revealed that pre-treatment of cells with PF108, P-MWNTs, or N-MWNTs did not reduce their MFI compared to the control cells. In addition, the fluorescence was unaffected by $\mathrm{TB}$, evidence that the fluorescence was from internalized E. coli in these cells. However, cells pre-treated with C-MWNTs had a 30\% reduction in MFI, even though the fluorescence was, again, highly resistant to quenching by TB. These results support the idea that C-MWNT accumulation impairs E. coli clearance by macrophages. In addition, the resistance to TB quenching in the control and cells pre-treated with MWNTs also implies that the plasma membrane of the cells was intact.

\subsection{Reduced OxLDL Uptake by RAW 264.7 Cells Pre-Exposed to C-MWNTs, but Not P-or N-MWNTs}

SR-A1 is one of the three major SRs involved in the recognition and uptake of oxLDL by macrophages, in addition to CD36 and LOX-1 [36]. The uptake and the subsequent intracellular accumulation of oxLDL have been shown to promote the transformation of lipid-laden macrophages to foam cells with proatherogenic effects [36-38]. The effect of MWNTs on the uptake of oxLDL was tested with RAW 264.7 cells using the schematic experimental approach shown in Figure 8A. Cells were incubated in media containing either $0.1 \mathrm{mM}$ PF108 alone, $100 \mu \mathrm{g} / \mathrm{mL} \mathrm{P}_{-}, \mathrm{N}_{-}$, or C-MWNTs, or in 
control medium that contained no PF108 or MWNTs for $20 \mathrm{~h}$ at $37^{\circ} \mathrm{C}$. After this pre-treatment, the cells were washed and incubated in fresh serum-free medium for $4 \mathrm{~h}$ at $37^{\circ} \mathrm{C}$ to remove lipid components in the culture medium and then exposed to Alexa Fluor ${ }^{\circledR} 488$-conjugated oxLDL for $2 \mathrm{~h}$ at $37^{\circ} \mathrm{C}$ in the dark. Cells were washed and assessed for phagocytosed oxLDL by epi-fluorescence microscopy (FM) and FCyt analysis. Representative fluorescence images of untreated control and MWNT-treated cells are shown in Figure 8B. Active uptake of fluorescent oxLDL was readily visible in untreated control and cells treated with P- or N-MWNTs, whereas green fluorescence was reduced in C-MWNT-treated cells, correlating C-MWNT accumulation with impaired oxLDL uptake by RAW 264.7 cells.

Quantitative results of FCyt analysis (Figure 8C) confirmed the qualitative FM observations shown in Figure 8B. The untreated control and cells exposed to either PF108 alone, P-, or N-MWNTs all had active oxLDL uptake, with mean fluorescence intensities of $2.5 \times 10^{5}, 2.8 \times 10^{5}, 3.0 \times 10^{5}$, and $3.1 \times 10^{5}$, respectively, indicative of robust phagocytic activities in these cells. On the contrary, cells with accumulated C-MWNTs displayed a significantly lower fluorescence intensity of $1.3 \times 10^{5}$, indicative of a reduced activity (by $\sim 50 \%$ ) for oxLDL uptake (Figure $8 \mathrm{C}$ ). These data, again, support the idea that the accumulation of C-MWNTs impairs the subsequent uptake of SR-A1 receptor ligands.

The concern that C-MWNTs may have quenching effects on the internalized fluorescent oxLDL was addressed with independent oxLDL uptake experiments using non-fluorescent oxLDL. The development of oil droplets from oxLDL uptake by cells was detected visually and measured quantitatively based on an ORO staining assay [39-41], with optimization detailed in the Methods section. RAW 264.7 cells seeded on glass coverslips were pre-treated either with regular culture medium as control or with test media containing $100 \mu \mathrm{g} / \mathrm{mL}$ of $\mathrm{P}_{-}, \mathrm{N}_{-}$, or C-MWNTs at $37^{\circ} \mathrm{C}$ for $24 \mathrm{~h}$. After pre-treatment, cells were washed and serum-starved for $4 \mathrm{~h}$ before exposure to non-fluorescent oxLDL for $16 \mathrm{~h}$. The uptake of oxLDL was detected as red oil droplets stained with ORO dye. The red stained oil droplets were readily visible under a bright-field microscope with LED transmitted light and a 40× magnification objective lens. In addition, the ORO stain was eluted in isopropanol and measured quantitatively as absorbance intensity at $510 \mathrm{~nm}$.

Representative ORO stained images of control and MWNT-treated cells, with and without oxLDL exposure, are shown in SI Figure S7B. Without oxLDL exposure, no ORO stains were visible in either control or any of the MWNT-treated cells, indicating that endogenous oil droplets were successfully depleted during the serum starvation period. On the contrary, robust oxLDL uptake was evidenced by the red ORO stain in cells allowed to take up oxLDL present in the media. Notice that internalized MWNTs were clearly visible as dark gray vesicular structures inside cells pre-treated with C-MWNTs that may obstruct visual assessment of red oil droplets in these cells. Thus, cell-associated ORO was determined by extracting the dye from cells with isopropanol, and the eluent was then transferred to new plates and measured spectrophotometrically free of potential MWNT interference. Results of the quantitative oxLDL uptake assessment, represented by the relative ORO stain intensities of the untreated control and cells pre-treated with MWNTs, indicated that oxLDL uptake was reduced by $\sim 30 \%$ in cells pre-treated with C-MWNTs, whereas P- or N-MWNTs had no effect on subsequent oxLDL uptake (SI Figure S7C). These results agree with data in Figure 8 using fluorescent oxLDL and validate the finding that accumulation of C-MWNTs in RAW 264.7 cells affects subsequent phagocytosis of oxLDL. 
(A) Experimental Scheme

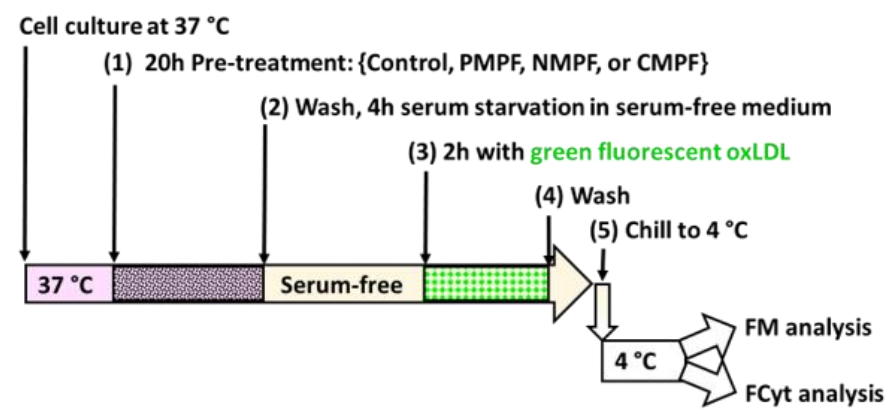

(B) Representative FM Images of RAW 264.7 Cells with Phagocytosed Green Fluorescent oxLDL
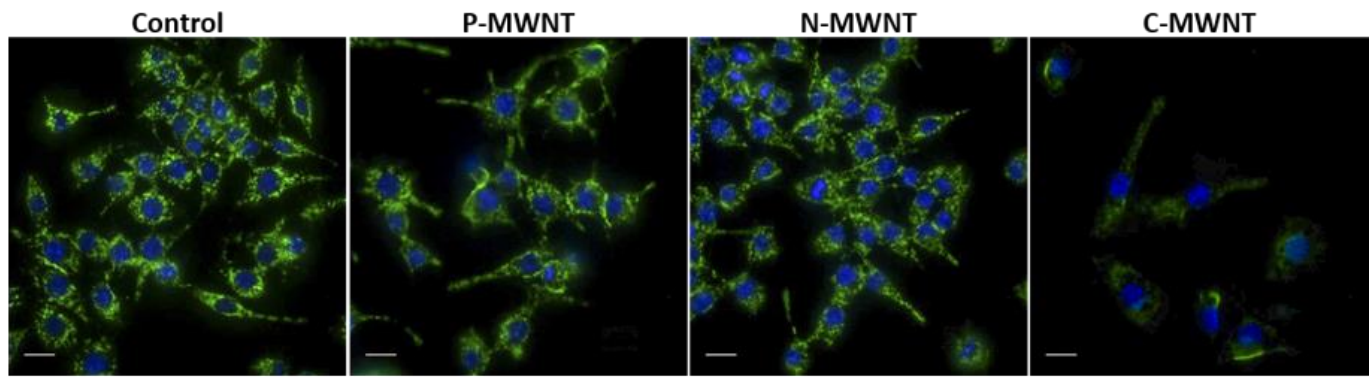

(C) Assessment of Phagocytosed Green Fluorescent oxLDL in RAW 264.7 Cells by FCyt
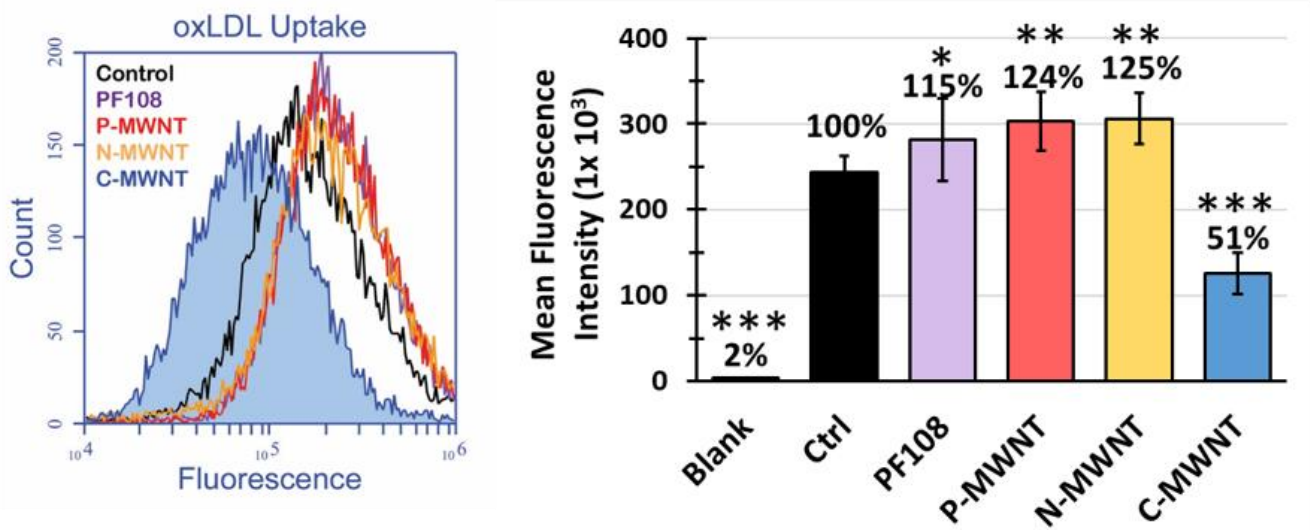

Figure 8. Reduced fluorescent oxLDL uptake by RAW 264.7 cells pre-treated with C-MWNTs, but not P- or N-MWNTs. RAW 264.7 cells were incubated in media containing either $0.1 \mathrm{mM}$ PF108 alone or $100 \mu \mathrm{g} / \mathrm{mL}$ of $\mathrm{P-}, \mathrm{N}-$, or C-MWNTs at $37^{\circ} \mathrm{C}$ for $24 \mathrm{~h}$. Untreated control cells were incubated in regular culture medium in the absence of PF108 surfactant or MWNTs. After the pre-treatments, cells were washed and serum starved for $4 \mathrm{~h}$ in serum-free medium before incubation in fresh serum-free medium containing Alexa Fluor ${ }^{\circledR}$ 488-conjugated oxLDL (1:20 dilution for FM and 1:40 dilution for FCyt) for $2 \mathrm{~h}$ at $37^{\circ} \mathrm{C}$. Cells were washed again, chilled to $4{ }^{\circ} \mathrm{C}$, and prepared for FM or FCyt as described in Methods. (A) The timeline schematic outlining the key experimental steps. (B) Representative epi-fluorescence images of the control and treated cells. Blue fluorescence is emitted from Hoechst 33342 stained nuclei and green fluorescence is from internalized Alexa Fluor ${ }^{\circledR}$ 488-conjugated oxLDL. (C) Representative fluorescence histograms of control cells (black), cells pre-treated with $0.1 \mathrm{mM}$ PF108 (purple), $100 \mu \mathrm{g} / \mathrm{mL}$ of P-MWNTs (red), N-MWNTs (yellow), or C-MWNTs (blue) are plotted on the left. The internalized oxLDL is represented as the mean fluorescence intensity of a total of 10,000 cells analyzed per sample and plotted as a bar graph on the right. Data are the mean \pm SD of triplicate samples in $\geq 4$ independent experiments. Percent values shown above the bars indicate mean fluorescence intensity relative to untreated control cells where the level of oxLDL was set to $100 \%$. ${ }^{*}$ is for $p<5.0 \times 10^{-2}$, ** is for $p<5.0 \times 10^{-5}$, and ${ }^{* * *}$ is for $p<5.0 \times 10^{-10}$ against control. 


\section{Discussion}

Our present hypothesis for the selective interaction of PF108-coated C-MWNTs with macrophages is that the primary determinant of the interaction is oxidative functionalities on nanotubes, which could include carboxylation, hydroxylation, and other carbon-oxygen bonded groups. This idea is supported by our previous work comparing various physical properties of the carbon nanotubes that are highly accumulated by cells. Both carboxylated single-walled carbon nanotubes (C-SWNTs) as well as C-MWNTs are highly accumulated, but not their pristine counterparts, suggesting that neither nanotube diameter nor chirality are critical parameters for accumulation [11]. Moreover, both short and long C-MWNTs were accumulated, so length is apparently not a factor [11]. It is unlikely that the non-ionic Pluronic ${ }^{\circledR}$ coat on the nanotubes influences interactions with cells because both carboxylated and pristine nanotubes bear the same coat yet they bind and accumulate differently. It is also notable that a protein corona is not required for receptor interaction as binding to cells occurs at $4{ }^{\circ} \mathrm{C}$ in the absence of serum [11]. The zeta potentials of the carboxylated nanotubes are more negative than their pristine counterparts, as expected, and a negative charge is a common physical feature related to carboxylation shared by nanotubes that are highly accumulated. Members of Class A SRs interact with certain anionic ligands and polyanions such as dextran sulfate often antagonize this interaction. Dextran sulfate and similar compounds were previously noted to affect the response of cells to carbon nanotubes, suggesting that scavenger receptors may be involved [42-44]. In addition, Singh et al. observed that increased carboxylation of MWNTs correlated with MWNT accumulation at $37^{\circ} \mathrm{C}$ by RAW 264.7 cells, and accumulation was inhibited by dextran sulfate [45]. We previously noted that dextran sulfate partially inhibits the binding of C-MWNTs to cells at $4{ }^{\circ} \mathrm{C}$ and accumulation at $37^{\circ} \mathrm{C}$, suggesting that SR-A members might be C-MWNT receptors [11]. However, data from inhibitor studies can be difficult to interpret when assigning a ligand interaction to a specific receptor, especially with scavenger receptors that often share similar binding domain structures. One main objective of the present study was to test the hypothesis that SR-A1 is a receptor for C-MWNTs using cell lines that either do or do not express SR-A1, a more informative approach than using inhibitors of ligand binding.

ZK alveolar macrophages, derived from SR-A1/MARCO deficient mice [22], were verified to lack SR-A1 and MARCO by FCyt. B6 cells, a wild type alveolar macrophage control, were positive for SR-A1, as was the established alveolar macrophage-derived cell line RAW 264.7. Both B6 and RAW 264.7 cells robustly accumulated C-MWNTs during a $24 \mathrm{~h}$ exposure, while ZK cells did not, thus correlating the presence of SR-A1 with the capacity to accumulate C-MWNTs. None of the cells expressed significant levels of MARCO making it unlikely that MARCO contributes to C-MWNT uptake by B6 and RAW 264.7 cells. However, this does not imply that MARCO cannot bind C-MWNTs because MARCO, like SR-A1, contains a collagenous domain believed to bind polyanionic ligands. In fact, it was observed that ectopic expression of MARCO in CHO cells enhanced the uptake of MWNTs [46]. Therefore, MARCO may be involved in C-MWNTs uptake by other cell types that express this scavenger receptor. N-MWNTs, like P-MWNTs, did not accumulate in any of the cells tested, consistent with the idea that the anionic carboxyl groups of C-MWNTs are a determinant of receptor-mediated uptake.

$\mathrm{CHO}[\mathrm{mSR}-\mathrm{AI}]$ cells that express SR-A1 were studied to determine whether SR-A1 expression caused a gain in the capacity to accumulate C-MWNTs. As received $\mathrm{CHO}$ [mSR-AI] cells were re-cloned and all three clones were positive for surface SR-A1 by FCyt compared to wild type CHO-K1 cells and all three clones accumulated C-MWNTs, but not P-MWNTs or N-MWNTs. In summary, cells that did not express SR-A1 did not accumulate C-MWNTs, while those that expressed SR-A1 did accumulate C-MWNTs, strong evidence that SR-A1 is a C-MWNT receptor and functions in the receptor-mediated uptake of C-MWNTs.

A corona of proteins derived from biological fluids is often believed to be a major determinant in the interaction of engineered nanoparticles with cells [47-50]. For C-MWNTs coated with Pluronic ${ }^{\circledR}$, since binding and uptake can occur in the absence of serum, the major determinant of C-MWNT binding and accumulation appears to be the oxidized functionalities and not a protein corona on the MWNT surface; nevertheless, serum is a dose dependent inhibitor of binding [11]. This suggests that 
something in serum either interacts with C-MWNTs, with SR-A1, or both, to influence accumulation. Thus, although a protein corona derived from serum is not necessary for C-MWNTs to bind to cells, it may still affect interactions if present. Moreover, it should be possible to increase the complexity of the model system by adding a defined protein corona to C-MWNTs to determine whether carboxylation still contributes to the interaction of nanotubes with SR-A1 and whether the protein expands interactions to other receptors.

A second objective of this study was to assess the effects on cell viability of short- and long-term exposure of SR-A1-positive cells to MWNTs. Apoptosis was measured by flow cytometry using an apoptotic/dead cell kit after a $24 \mathrm{~h}$ exposure of RAW 264.7 cells to MWNTs $(100 \mu \mathrm{g} / \mathrm{mL})$, and there was no significant difference among cells treated with PF108 alone and cells treated with C-MWNTs, P-MWNTs and N-MWNTs, compared to a positive control of CPT treated cells where apoptosis was obvious. In previous work, we found that a $24 \mathrm{~h}$ exposure to C-MWNTs had little effect on cell proliferation [11], and here we compared cell proliferation as a function of MWNT concentration at 24, 48, and $72 \mathrm{~h}$. Beyond $24 \mathrm{~h}, \mathrm{C}-\mathrm{MWNTs}$ more adversely affected proliferation than P-MWNTs and N-MWNTs. By $72 \mathrm{~h}$, the IC50 for C-MWNTs was $~ 80 \mu \mathrm{g} / \mathrm{mL}$ whereas P-MWNTs had not reached an IC50 at $200 \mu \mathrm{g} / \mathrm{mL}$ and N-MWNTs had barely reached IC50 at $200 \mu \mathrm{g} / \mathrm{mL}$, the highest MWNT concentration tested. Because exposure time was an important parameter in toxicity experiments, colony formation efficiency assays were done where cells were continuously exposed to different MWNT concentrations for 8 day. After an 8-d exposure to $100 \mu \mathrm{g} / \mathrm{mL}$ C-MWNTs, there were essentially no colonies formed whereas P-MWNTs and N-MWNTs had $\sim 40 \%$ colony formation efficiency compared to the untreated control under the same condition. The IC50 for C-MWNTs was $\sim 29 \mu \mathrm{g} / \mathrm{mL}$, but there was a reduction in colony formation efficiency even in the range of a few $\mu \mathrm{g} / \mathrm{mL}$, which is important as it suggests that even low doses of C-MWNTs over time may accumulate and adversely affect cells. These data emphasize that C-MWNTs are more toxic than P-MWNTs or N-MWNTs, especially after longer exposures, which is not surprising considering that RAW 264.7 cells accumulate about 80-100 times more C-MWNTs than P-MWNTs or N-MWNTs in $24 \mathrm{~h}$. However, it is also notable that for a given IC-50, the amount of C-MWNTs in the cell on a per cell basis is much higher than for P-MWNTs or N-MWNTs, indicating that on an MWNT weight basis per cell, C-MWNTs appear to be less toxic than P-MWNTs or N-MWNTs. Thus, long-term exposure to MWNTs at lower concentration, regardless of carboxylation, may affect cell viability.

A third objective of this study was to assess what might be the spectrum of physiological consequences to macrophage functions after exposure to MWNTs, specifically related to the interaction of C-MWNTs with SR-A1. One possibility is that internalization of surface SR-A1/C-MWNT complexes could deplete the plasma membrane of SR-A1 receptors. To assess this, cells were treated with MWNTs at $37^{\circ} \mathrm{C}$ followed by immunofluorescence detection of surface SR-A1 with a specific antibody, using both qualitative IFM images and quantitative FCyt analysis. In untreated cells and those treated with P-MWNTs or N-MWNTs, SR-A1 was present in punctate spots that are believed to be receptors clustered in lipid rafts scattered over the cell surface [33]. However, after C-MWNT treatment, the overall surface SR-A1 signal was reduced and redistributed mainly to the cell margins. The reason for this abnormal distribution is not clear, but it might adversely affect SR-A1 function. In addition, the fluorescent signal from C-MWNT-treated cells by FCyt analysis was reduced by about $40 \%$ whereas the signal from P-MWNT- or N-MWNT-treated cells was much less affected. A concern in the interpretation of the FCyt results is that C-MWNTs might interfere with the fluorescence signal, even though the internalized C-MWNTs are mainly within intracellular vesicles and the fluorescent anti-SR-A1 is on the cell surface. To address this concern, cells were treated with MWNTs at $4{ }^{\circ} \mathrm{C}$ to allow binding, then chased for an hour at either 37 or $4{ }^{\circ} \mathrm{C}$. The $37^{\circ} \mathrm{C}$ chase was to allow surface MWNTs to be internalized and the $4{ }^{\circ} \mathrm{C}$ treatment was to keep them on the cell surface. Fluorescent monoclonal anti-SR-A1 was then added at $4{ }^{\circ} \mathrm{C}$ and the fluorescence signal was measured by FCyt. There was no attenuation of the surface fluorescence signal by C-MWNTs, suggesting that C-MWNTs have little influence on the signal of anti-SR-A1 antibody regardless of whether the MWNTs were internalized or on the cells surface. 
These data are consistent with the idea that internalization of C-MWNTs via SR-A1 depletes the cell surface of this important receptor.

The ability of C-MWNT-treated RAW 264.7 cells to respond to several known SR-A1 ligands was also examined. The internalization of fluorescent polystyrene beads measured by FCyt was impaired by over $50 \%$ after C-MWNT treatment, but not markedly affected after P-MWNT or N-MWNT treatment. Note also that ZK cells lacking SR-A1 failed to accumulate beads when untreated with C-MWNTs, verifying that SR-A1 was a receptor for the beads. We previously reported that the uptake of non-fluorescent polystyrene beads by RAW 264.7 cells treated with C-MWNTs for 2 or $20 \mathrm{~h}$ was reduced by 2 -fold and 6-fold, respectively, when assayed by directly counting the number of beads in cells [11]. This adds confidence that the decline in the fluorescence signal from internalized beads in C-MWNT-treated cells is not an artifact of fluorescence quenching by cell-associated C-MWNTs.

The uptake of heat-killed Alexa Fluor ${ }^{\circledR} 488$-conjugated E. coli was measured as another model system to assess SR-A1 function after MWNT treatment. RAW 264.7 cells treated with or without MWNTs for $24 \mathrm{~h}$ were chilled and incubated with E. coli at $4{ }^{\circ} \mathrm{C}$ low temperature to load receptors, followed by incubation at $37^{\circ} \mathrm{C}$ to permit internalization. Cells treated with P-MWNTs or N-MWNTs showed no decline in fluorescence signal whereas cells treated with C-MWNTs showed a $30 \%$ decline, evidence that the clearance of a physiologically relevant SR-A1 ligand is affected. In these experiments, the ability of trypan blue to quench Alexa Fluor ${ }^{\circledR} 488$ was used to verify that the fluorescent $E$. coli were inside the cell sheltered from contact with trypan blue, which does not penetrate the plasma membrane of intact cells.

The final SR-A1 ligand studied was oxLDL. One assay measured the accumulation of fluorescent oxLDL by FCyt and another used a non-fluorescence-based approach to measure the development of fat droplets induced by oxLDL accumulation. Both assays revealed reduced oxLDL accumulation by cells treated with C-MWNTs but not with P-MWNTs or N-MWNTs, confirming that another important function of SR-A1, the clearance of oxLDL, was impaired.

In summary, the uptake of three different SR-A1 ligands was impaired in RAW 264.7 cells by C-MWNT accumulation. One major factor affecting the uptake is likely to be the reduced number of SR-A1 receptors on the cell surface. Impaired functionality related to one or more of these ligands could contribute to the observed reduced viability of C-MWNT-treated cells. Thus, there are likely related adverse consequences affecting other biological functions, in addition to impaired SR-A1 functions demonstrated here, resulting from selective C-MWNT uptake in macrophages.

\section{Conclusions}

The binding and accumulation of Pluronic ${ }^{\circledR}$-coated MWNTs described here provides a model system where key experimental parameters of the interaction of carbon nanomaterials with cells can be controlled. One feature of the approach is the SDS-PAGE assay that quantitates nanotubes extracted from cells, enabling the direct measurement of nanotube binding and accumulation by cells. In addition, binding of MWNTs to cell surface receptors can be determined at $4{ }^{\circ} \mathrm{C}$ and in the absence of serum where other physiological activities, such as endocytosis, vesicle recycling, enzymatic degradation, or interaction influenced by serum proteins corona were curtailed. The approach permitted the direct observation that carboxylated nanotubes, but not pristine or amino-functionalized counterparts, could selectively bind to and be accumulated by cells, suggesting that there were receptors that recognized carboxylated nanotubes. The results of studies with cells that either over or under express SR-A1 strongly implicate SR-A1 as the key receptor for carboxylated nanotubes. Two lines of evidence also suggest that there are adverse consequences of nanotube accumulation related to SR-A1 functions. First, the uptake of three different SR-A1 ligands (polystyrene beads, E. coli, and oxLDL) was impaired in RAW 264.7 cells laden with C-MWNT, emphasizing that pathogen clearance and lipid homeostasis could be affected in macrophages exposed to C-MWNTs. Second, C-MWNT uptake via SR-A1 leads to a concentration and time dependent reduction in the viability of alveolar macrophages. The results of 
this study may have implications for other oxidized carbon nanomaterials and it would be interesting to know if graphene oxide and carbon-based quantum dots also bind SR-A1.

Supplementary Materials: The following are available online at http://www.mdpi.com/2079-4991/10/12/2417/s1, Figure S1: MWNTs induce mild apoptosis in RAW 264.7 cells. Figure S2: Representative 3D video clips of control and C-MWNT-treated RAW 264.7 cells immuno-fluorescent stained for surface SR-A1 receptors. Figure S3: Surface-bound or phagocytosed MWNTs do not interfere with immunofluorescence FCyt assays for surface SR-A1 receptors on RAW 264.7 cells. Figure S4: Effects of MWNT accumulation on subsequent phagocytosis of polystyrene beads in WT B6 and $\mathrm{MS}^{-1-}$ ZK cells assessed by LSCFM. Figure S5: Fluorescence quenching of fluorescent-conjugated, heat killed E. coli particles by trypan blue dye. Figure S6: Laser scanning confocal Raman microscopy analysis of RAW 264.7 cells with phagocytosed polystyrene beads in the present or absence of C-MWNTs. Figure S7: Reduced oxLDL uptake by RAW 264.7 cells pre-treated with C-MWNTs, but not P- or $\mathrm{N}-\mathrm{MWNTs}$, assessed using ORO staining assays. (Directions to access the SI will be updated in the final version of the manuscript.)

Author Contributions: Conceptualization, R.W. and R.D.; methodology, R.W.; investigation, R.W., R.L., E.C., P.G. and L.S.; resources, R.D.; writing —original draft preparation, R.W. and R.D.; writing-review and editing, R.L., E.C., P.G., and L.S.; supervision, R.W. and R.D; funding acquisition, R.D. All authors have read and agreed to the published version of the manuscript.

Funding: This research was funded by Research Enhancement Funds from the University of Texas at Dallas provided to R.D., E.C. and P.G. were recipients of Undergraduate Research Scholar Awards from the University of Texas at Dallas.

Acknowledgments: The authors are grateful to the Undergraduate Research Fund of the University of Texas at Dallas School of Natural Sciences and Mathematics for the support of undergraduate students.

Conflicts of Interest: The authors declare no conflict of interest.

\section{References}

1. De Volder, M.F.L.; Tawfick, S.H.; Baughman, R.H.; Hart, A.J. Carbon Nanotubes: Present and Future Commercial Applications. Science 2013, 339, 535-539. [CrossRef] [PubMed]

2. Serpell, C.J.; Kostarelos, K.; Davis, B.G. Can Carbon Nanotubes Deliver on Their Promise in Biology? Harnessing Unique Properties for Unparalleled Applications. ACS Cent. Sci. 2016, 2, 190-200. [CrossRef]

3. Rao, R.; Pint, C.L.; Islam, A.E.; Weatherup, R.S.; Hofmann, S.; Meshot, E.R.; Wu, F.; Zhou, C.; Dee, N.; Amama, P.B.; et al. Carbon Nanotubes and Related Nanomaterials: Critical Advances and Challenges for Synthesis toward Mainstream Commercial Applications. ACS Nano 2018, 12, 11756-11784. [CrossRef] [PubMed]

4. Pauluhn, J. Subchronic 13-Week Inhalation Exposure of Rats to Multiwalled Carbon Nanotubes: Toxic Effects Are Determined by Density of Agglomerate Structures, Not Fibrillar Structures. Toxicol. Sci. 2009, 113, 226-242. [CrossRef] [PubMed]

5. Pothmann, D.; Simar, S.; Schuler, D.; Dony, E.; Gaering, S.; Le Net, J.-L.; Okazaki, Y.; Chabagno, J.M.; Bessibes, C.; Beausoleil, J.; et al. Lung inflammation and lack of genotoxicity in the comet and micronucleus assays of industrial multiwalled carbon nanotubes Graphistrength (C) C100 after a 90-day nose-only inhalation exposure of rats. Part. Fibre Toxicol. 2015, 12, 21. [CrossRef]

6. Poland, C.A.; Duffin, R.; Kinloch, I.; Maynard, A.; Wallace, W.A.; Seaton, A.; Stone, V.; Brown, S.; Macnee, W.; Donaldson, K. Carbon nanotubes introduced into the abdominal cavity of mice show asbestos-like pathogenicity in a pilot study. Nat. Nanotechnol. 2008, 3, 423-428. [CrossRef]

7. Kato, T.; Totsuka, Y.; Ishino, K.; Matsumoto, Y.; Tada, Y.; Nakae, D.; Goto, S.; Masuda, S.; Ogo, S.; Kawanishi, M.; et al. Genotoxicity of multi-walled carbon nanotubes in both in vitro and in vivo assay systems. Nanotoxicology 2013, 7, 452-461. [CrossRef]

8. Suzui, M.; Futakuchi, M.; Fukamachi, K.; Numano, T.; Abdelgied, M.; Takahashi, S.; Ohnishi, M.; Omori, T.; Tsuruoka, S.; Hirose, A.; et al. Multiwalled carbon nanotubes intratracheally instilled into the rat lung induce development of pleural malignant mesothelioma and lung tumors. Cancer Sci. 2016, 107, 924-935. [CrossRef]

9. Ravi Kiran, A.V.V.V.; Kusuma Kumari, G.; Krishnamurthy, P.T. Carbon nanotubes in drug delivery: Focus on anticancer therapies. J. Drug Deliv. Sci. Technol. 2020, 59, 101892. [CrossRef]

10. Zhang, Y.-N.; Poon, W.; Tavares, A.J.; McGilvray, I.D.; Chan, W.C.W. Nanoparticle-liver interactions: Cellular uptake and hepatobiliary elimination. J. Control. Release 2016, 240, 332-348. [CrossRef] 
11. Wang, R.; Lee, M.; Kinghorn, K.; Hughes, T.; Chuckaree, I.; Lohray, R.; Chow, E.; Pantano, P.; Draper, R. Quantitation of cell-associated carbon nanotubes: Selective binding and accumulation of carboxylated carbon nanotubes by macrophages. Nanotoxicology 2018, 12, 677-690. [CrossRef] [PubMed]

12. Kelley, J.L.; Ozment, T.R.; Li, C.; Schweitzer, J.B.; Williams, D.L. Scavenger receptor-A (CD204): A two-edged sword in health and disease. Crit. Rev. Immunol. 2014, 34, 241-261. [CrossRef] [PubMed]

13. Zani, I.; Stephen, S.; Mughal, N.; Russell, D.; Homer-Vanniasinkam, S.; Wheatcroft, S.; Ponnambalam, S. Scavenger receptor structure and function in health and disease. Cells 2015, 4, 178. [CrossRef] [PubMed]

14. PrabhuDas, M.R.; Baldwin, C.L.; Bollyky, P.L.; Bowdish, D.M.E.; Drickamer, K.; Febbraio, M.; Herz, J.; Kobzik, L.; Krieger, M.; Loike, J.; et al. A Consensus Definitive Classification of Scavenger Receptors and Their Roles in Health and Disease. J. Immunol. 2017, 198, 3775-3789. [CrossRef]

15. Maler, M.D.; Nielsen, P.J.; Stichling, N.; Cohen, I.; Ruzsics, Z.; Wood, C.; Engelhard, P.; Suomalainen, M.; Gyory, I.; Huber, M.; et al. Key Role of the Scavenger Receptor MARCO in Mediating Adenovirus Infection and Subsequent Innate Responses of Macrophages. mBio 2017, 8, e06670-17. [CrossRef] [PubMed]

16. Rausch, J.; Zhuang, R.-C.; Mäder, E. Surfactant assisted dispersion of functionalized multi-walled carbon nanotubes in aqueous media. Compos. Part A Appl. Sci. Manuf. 2010, 41, 1038-1046. [CrossRef]

17. White, C.M.; Banks, R.; Hamerton, I.; Watts, J.F. Characterisation of commercially CVD grown multi-walled carbon nanotubes for paint applications. Prog. Org. Coat. 2016, 90, 44-53. [CrossRef]

18. Wang, R.; Hughes, T.; Beck, S.; Vakil, S.; Li, S.; Pantano, P.; Draper, R.K. Generation of toxic degradation products by sonication of Pluronic ${ }^{\mathrm{R}}$ dispersants: Implications for nanotoxicity testing. Nanotoxicology 2013, 7, 1272-1281. [CrossRef] [PubMed]

19. Wang, R.; Meredith, N.A.; Lee, M., Jr.; Deutsch, D.; Miadzvedskaya, L.; Braun, E.; Pantano, P.; Harper, S.; Draper, R. Toxicity assessment and bioaccumulation in zebrafish embryos exposed to carbon nanotubes suspended in Pluronic(R) F-108. Nanotoxicology 2016, 10, 689-698. [CrossRef]

20. Nakata, T. Destruction of challenged endotoxin in a dry heat oven. PDA J. Pharm. Sci. Technol. 1994, 48, 59-63.

21. Wang, R.; Murali, V.S.; Draper, R. Detecting Sonolysis of Polyethylene Glycol upon Functionalizing Carbon Nanotubes. In Cancer Nanotechnology: Methods and Protocols; Zeineldin, R., Ed.; Springer: New York, NY, USA, 2017; pp. 147-164. [CrossRef]

22. Zhou, H.; Imrich, A.; Kobzik, L. Characterization of immortalized MARCO and SR-AI/II-deficient murine alveolar macrophage cell lines. Part. Fibre Toxicol. 2008, 5, 7. [CrossRef] [PubMed]

23. Ashkenas, J. Structures and high and low affinity ligand binding properties of murine type I and type II macrophage scavenger receptors. J. Lipid Res. 1993, 34, 983-1000. [PubMed]

24. Wang, R.; Mikoryak, C.; Li, S.; Bushdiecker II, D.; Musselman, I.H.; Pantano, P.; Draper, R.K. Cytotoxicity screening of single-walled carbon nanotubes: Detection and removal of cytotoxic contaminants from carboxylated carbon nanotubes. Mol. Pharm. 2011, 8, 1351-1361. [CrossRef] [PubMed]

25. Franken, N.A.P.; Rodermond, H.M.; Stap, J.; Haveman, J.; van Bree, C. Clonogenic assay of cells in vitro. Nat. Protoc. 2006, 1, 2315-2319. [CrossRef]

26. Sahlin, S.; Hed, J.; Runfquist, I. Differentiation between attached and ingested immune complexes by a fluorescence quenching cytofluorometric assay. J. Immunol. Methods 1983, 60, 115-124. [CrossRef]

27. Busetto, S.; Trevisan, E.; Patriarca, P.; Menegazzi, R. A single-step, sensitive flow cytofluorometric assay for the simultaneous assessment of membrane-bound and ingested Candida albicans in phagocytosing neutrophils. Cytom. Part A 2004, 58A, 201-206. [CrossRef]

28. Herzog, E.; Casey, A.; Lyng, F.M.; Chambers, G.; Byrne, H.J.; Davoren, M. A new approach to the toxicity testing of carbon-based nanomaterials-The clonogenic assay. Toxicol. Lett. 2007, 174, 49-60. [CrossRef]

29. Gellein, K.; Hoel, S.; Gellein, K.; Hoel, S.; Evje, L.; Syversen, T. The colony formation assay as an indicator of carbon nanotube toxicity examined in three cell lines. Nanotoxicology 2009, 3, 215-221. [CrossRef]

30. Morris, E.J.; Geller, H.M. Induction of neuronal apoptosis by camptothecin, an inhibitor of DNA topoisomerase-I: Evidence for cell cycle-independent toxicity. J. Cell Biol. 1996, 134, 757-770. [CrossRef]

31. Dunne, D.W.; Resnick, D.; Greenberg, J.; Krieger, M.; Joiner, K.A. The type I macrophage scavenger receptor binds to gram-positive bacteria and recognizes lipoteichoic acid. Proc. Natl. Acad. Sci. USA 1994, 91, 1863-1867. [CrossRef]

32. Steinberg, D. Low Density Lipoprotein Oxidation and Its Pathobiological Significance. J. Biol. Chem. 1997, 272, 20963-20966. [CrossRef] [PubMed] 
33. Nagao, G.; Ishii, K.; Hirota, K.; Makino, K.; Terada, H. Role of Lipid Rafts in Phagocytic Uptake of Polystyrene Latex Microspheres by Macrophages. Anticancer Res. 2010, 30, 3167-3176. [PubMed]

34. Ordija, C.M.; Chiou, T.T.; Yang, Z.; Deloid, G.M.; de Oliveira Valdo, M.; Wang, Z.; Bedugnis, A.; Noah, T.L.; Jones, S.; Koziel, H.; et al. Free actin impairs macrophage bacterial defenses via scavenger receptor MARCO interaction with reversal by plasma gelsolin. Am. J. Physiol. Lung Cell. Mol. Physiol. 2017, 312, L1018-L1028. [CrossRef] [PubMed]

35. Hampton, R.Y.; Golenbock, D.T.; Penman, M.; Krieger, M.; Raetz, C.R.H. Recognition and plasma clearance of endotoxin by scavenger receptors. Nature 1991, 352, 342-344. [CrossRef] [PubMed]

36. Moore, K.J.; Tabas, I. Macrophages in the Pathogenesis of Atherosclerosis. Cell 2011, 145, 341-355. [CrossRef] [PubMed]

37. Nagy, L.; Tontonoz, P.; Alvarez, J.G.A.; Chen, H.; Evans, R.M. Oxidized LDL Regulates Macrophage Gene Expression through Ligand Activation of PPAR $\gamma$. Cell 1998, 93, 229-240. [CrossRef]

38. Trpkovic, A.; Resanovic, I.; Stanimirovic, J.; Radak, D.; Mousa, S.A.; Cenic-Milosevic, D.; Jevremovic, D.; Isenovic, E.R. Oxidized low-density lipoprotein as a biomarker of cardiovascular diseases. Crit. Rev. Clin. Lab. Sci. 2015, 52, 70-85. [CrossRef]

39. Ramírez-Zacarías, J.L.; Castro-Muñozledo, F.; Kuri-Harcuch, W. Quantitation of adipose conversion and triglycerides by staining intracytoplasmic lipids with oil red O. Histochemistry 1992, 97, 493-497. [CrossRef]

40. Xu, S.; Huang, Y.; Xie, Y.; Lan, T.; Le, K.; Chen, J.; Chen, S.; Gao, S.; Xu, X.; Shen, X.; et al. Evaluation of foam cell formation in cultured macrophages: An improved method with Oil Red O staining and DiI-oxLDL uptake. Cytotechnology 2010, 62, 473-481. [CrossRef]

41. Kraus, N.A.; Ehebauer, F.; Zapp, B.; Rudolphi, B.; Kraus, B.J.; Kraus, D. Quantitative assessment of adipocyte differentiation in cell culture. Adipocyte 2016, 5, 351-358. [CrossRef]

42. Dutta, D.; Sundaram, S.K.; Teeguarden, J.G.; Riley, B.J.; Fifield, L.S.; Jacobs, J.M.; Addleman, S.R.; Kaysen, G.A.; Moudgil, B.M.; Weber, T.J. Adsorbed proteins influence the biological activity and molecular targeting of nanomaterials. Toxicol. Sci. 2007, 100, 303-315. [CrossRef]

43. Gao, N.; Zhang, Q.; Mu, Q.; Bai, Y.; Li, L.; Zhou, H.; Butch, E.R.; Powell, T.B.; Snyder, S.E.; Jiang, G.; et al. Steering carbon nanotubes to scavenger receptor recognition by nanotube surface chemistry modification partially alleviates NFKB activation and reduces its immunotoxicity. ACS Nano 2011, 5, 4581-4591. [CrossRef] [PubMed]

44. Wang, X.; Guo, J.; Chen, T.; Nie, H.; Wang, H.; Zang, J.; Cui, X.; Jia, G. Multi-walled carbon nanotubes induce apoptosis via mitochondrial pathway and scavenger receptor. Toxicol. Vitr. 2012, 26, 799-806. [CrossRef] [PubMed]

45. Singh, R.P.; Das, M.; Thakare, V.; Jain, S. Functionalization density dependent toxicity of oxidized multiwalled carbon nanotubes in a murine macrophage cell line. Chem. Res. Toxicol. 2012, 25, 2127-2137. [CrossRef] [PubMed]

46. Hirano, S.; Fujitani, Y.; Furuyama, A.; Kanno, S. Macrophage receptor with collagenous structure (MARCO) is a dynamic adhesive molecule that enhances uptake of carbon nanotubes by CHO-K1 Cells. Toxicol. Appl. Pharmacol. 2012, 259, 96-103. [CrossRef] [PubMed]

47. Fleischer, C.C.; Payne, C.K. Nanoparticle-Cell Interactions: Molecular Structure of the Protein Corona and Cellular Outcomes. Acc. Chem. Res. 2014, 47, 2651-2659. [CrossRef] [PubMed]

48. Feiner-Gracia, N.; Beck, M.; Pujals, S.; Tosi, S.; Mandal, T.; Buske, C.; Linden, M.; Albertazzi, L. Super-Resolution Microscopy Unveils Dynamic Heterogeneities in Nanoparticle Protein Corona. Small 2017, 13, 1701631. [CrossRef]

49. Liu, N.; Tang, M.; Ding, J. The interaction between nanoparticles-protein corona complex and cells and its toxic effect on cells. Chemosphere 2020, 245, 125624. [CrossRef]

50. You, D.J.; Lee, H.Y.; Bonner, J.C. Macrophages: First Innate Immune Responders to Nanomaterials. In Interaction of Nanomaterials with the Immune System; Bonner, J.C., Brown, J.M., Eds.; Springer International Publishing: Berlin/Heidelberg, Germany, 2020; pp. 15-34. [CrossRef]

Publisher's Note: MDPI stays neutral with regard to jurisdictional claims in published maps and institutional affiliations. 